\title{
Coherence between the Great Salt Lake Level and the Pacific Quasi-Decadal Oscillation
}

\author{
SHIH-YU WANG \\ Utah Climate Center, Utah State University, Logan, Utah
}

ROBERT R. GILLIES

Utah Climate Center, and Department of Plants, Soils, and Climate, Utah State University, Logan, Utah

JIMING JIN

Department of Plants, Soils, and Climate, and Department of Watershed Sciences, Utah State University, Logan, Utah

LAWRENCE E. HIPPS

Department of Plants, Soils, and Climate, Utah State University, Logan, Utah

(Manuscript received 12 December 2008, in final form 22 June 2009)

\begin{abstract}
The lake level elevation of the Great Salt Lake (GSL), a large closed basin lake in the arid western United States, is characterized by a pronounced quasi-decadal oscillation (QDO). The variation of the GSL elevation is very coherent with the QDO of sea surface temperature anomalies in the tropical central Pacific (also known as the Pacific QDO). However, such coherence denies any direct association between the precipitation in the GSL watershed and the Pacific QDO because, in a given frequency, the precipitation variation always leads the GSL elevation variation. Therefore, the precipitation variation is phase shifted from the Pacific QDO. This study investigates the physical mechanism forming the coherence between the GSL elevation and the Pacific QDO. Pronounced and coherent quasi-decadal signals in precipitation, streamflow, water vapor flux, and drought conditions are found throughout the Great Basin. Recurrent atmospheric circulation patterns develop over the Gulf of Alaska during the warm-to-cool and cool-to-warm transition phases of the Pacific QDO. These circulation patterns modulate the water vapor flux associated with synoptic transient activities over the western United States and, in turn, lead to the QDO in the hydrological cycle of the Great Basin. As the GSL integrates the hydrological responses in the Great Basin, the hydrological QDO is then transferred to the GSL elevation. Because the GSL elevation consistently lags the precipitation by a quarter-phase (about $3 \mathrm{yr}$ in the quasidecadal time scale), these processes take an average of $6 \mathrm{yr}$ for the GSL elevation to eventually respond to the Pacific QDO. This creates a half-phase delay of the GSL elevation from the Pacific QDO, thereby forming the inverse, yet coherent, relationship between them. Tree-ring reconstructed precipitation records confirm that the quasi-decadal signal in precipitation is a prominent feature in this region.
\end{abstract}

\section{Introduction}

The Great Salt Lake (GSL) of Utah, the fourth largest closed-basin lake in the world, is located in the intermountain region of the western United States where long-term climate fluctuations and droughts have prevailed in the recent decades (e.g., Cook et al. 1999). The

Corresponding author address: Shih-Yu (Simon) Wang, Utah Climate Center, Utah State University, 4825 Old Main Hill, Logan, UT 84322-4825.

E-mail: simon.wang@usu.edu
GSL integrates the hydrological response to precipitation in the Great Basin, while its large drainage area damps out high-frequency climatic variability (Lall and Mann 1995, hereafter LM95). As a result, the GSL elevation is very sensitive to low-frequency climate variations with relatively weak year-to-year fluctuations, as shown in Fig. 1. Numerous studies (LM95; Mann et al. 1995; Lall et al. 1996; Sangoyomi et al. 1996; Abarbanel and Lall 1996) have shown that lake level variations of the GSL are characterized by recurrent patterns, or cycles, at frequencies ranging from interdecadal to interannual time scales. In particular, the GSL elevation 


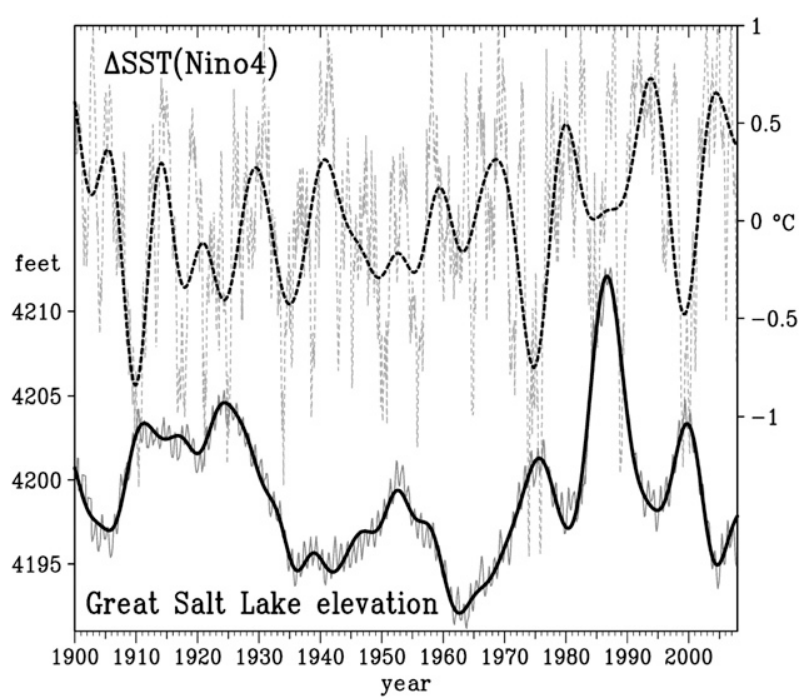

FIG. 1. Monthly GSL elevation (feet; thick solid curve) and the Kaplan v2 SST anomalies $\left({ }^{\circ} \mathrm{C}\right)$ in the Niño-4 region $\left(5^{\circ} \mathrm{S}-5^{\circ} \mathrm{N}\right.$, $\left.160^{\circ} \mathrm{E}-150^{\circ} \mathrm{W}\right)[\Delta \mathrm{SST}(\mathrm{Niño}-4)$; thick dashed curve], both smoothed by a 6-yr lowpass with the minimum slope constraint (Mann 2004). The original time series of the GSL elevation and $\Delta$ SST(Niño-4) are superimposed as a gray thin curve and a gray dashed curve, respectively.

was found to vary coherently with the Southern Oscillation index (SOI) at the quasi-decadal frequency of 12 yr (Moon and Lall 1996; Mann et al. 1995).

The quasi-decadal variation in the ocean and the atmosphere has been increasingly studied in the past decade. Recent works (Allan 2000; Tourre et al. 2001; White and Tourre 2003; Lohmann and Latif 2005) have identified the Pacific quasi-decadal oscillation (QDO) that may modulate the biennial activity of the El NiñoSouthern Oscillation (ENSO; White and Liu 2008a,b). In terms of sea surface temperature (SST) patterns, the Pacific QDO is noticeably different from ENSO: while the interannual ENSO mode features a narrow warm/ cold tongue dominating the central-eastern equatorial Pacific (i.e., the Niño- 3 region, $5^{\circ} \mathrm{N}-5^{\circ} \mathrm{S}, 150^{\circ}-90^{\circ} \mathrm{W}$ ), the Pacific QDO exhibits rather widespread warming/cooling areas centered at the central-western tropical Pacific (i.e., the Niño- 4 region, $5^{\circ} \mathrm{N}-5^{\circ} \mathrm{S}, 160^{\circ} \mathrm{E}-150^{\circ} \mathrm{W}$; Allan 2000; Tourre et al. 2001; Lohmann and Latif 2005). The coherent variation of the GSL elevation with the SOI (Moon and Lall 1996) implies that the GSL elevation also fluctuates at the same pace with SST in the central tropical Pacific. As indicated in Fig. 1, the SST anomalies in the Niño-4 region [denoted as $\Delta \mathrm{SST}$ (Niño-4) and smoothed by a 6-yr lowpass filter following Mann (2004)] appears to fluctuate in coherence yet opposite to the GSL elevation. Their out-of-phase association will be examined in this study. Since the Pacific QDO can be represented by $\Delta$ SST(Niño-4) (Allan 2000; Tourre et al. 2001), these two terms will be used interchangeably throughout the text.

As a closed-basin lake, variations in the GSL elevation closely follow the fluctuations in precipitation. It has been noted that precipitation and the GSL volume change (referring to the time rate of change of the GSL volume) are highly coherent in "all spectrums" (LM95) so that the GSL volume/elevation tends to lag the precipitation variation by a quarter-phase (Mann et al. 1995). Precipitation in the intermountain region, particularly in the southern and northern parts, is known to undergo modulations of ENSO (Dettinger et al. 1998; Cayan et al. 1999; Jin et al. 2006) and the Pacific decadal oscillation (PDO; Latif and Barnett 1994, 1996; Mantua et al. 1997; Gershunov and Barnett 1998). However, an out-of-phase relationship between the GSL elevation and $\Delta$ SST(Niño-4), as Fig. 1 reveals, is unique. The fact that the GSL elevation lags the precipitation variation by a quarter-phase implies that precipitation at the GSL should lag the Pacific QDO by a quarter-phase (i.e., a few years). If this is the case, then a direct link between $\Delta \mathrm{SST}(\mathrm{Niño}-4)$ and the precipitation variation, as that experienced in the north and south of the intermountain region, is absent. What causes the GSL elevation to vary so coherently with $\Delta$ SST(Niño-4) is therefore an intriguing question.

During the past half-century, a pronounced increase in the quasi-decadal variability was observed in the intermountain precipitation (Hidalgo and Dracup 2003; Wang et al. 2009, hereafter WGJH) as well as the GSL elevation (Fig. 1). WGJH found that the precipitation QDO in the intermountain region consistently lags the Pacific QDO by a quarter-phase: 3 yr after the warmphase Pacific QDO, an anomalous trough develops over the Gulf of Alaska and increases the intermountain precipitation through enhanced synoptic transients; and 3 yr after the cool-phase Pacific QDO, an anomalous ridge forms in the same area and thus reduces the precipitation. The Pacific QDO features an ENSO-like SST pattern and subsequently ENSO-like circulation anomalies in its warm and cool phases (e.g., Zhang et al. 1997; Tourre et al. 2001; Barlow et al. 2001). During the warmto-cool and cool-to-warm transitions, the widespread tropical warming/cooling vanishes (Tourre et al. 2001). However, a companion study (Wang et al. 2010) found that the transition-phase SST pattern redistributes the heating anomalies, which, in turn, induce an atmospheric short-wave train emanating from the tropical Western Pacific toward the Gulf of Alaska. Wang et al. (2010) noted that the regional circulation patterns linking to the precipitation QDO in the intermountain region are embedded in the downstream area of this shortwave train. 
The previous findings of the Pacific QDO teleconnection and the GSL variability lead to a hypothesis that the low-frequency coherence between the GSL elevation and $\Delta$ SST(Niño-4), as noted in Fig. 1, reflects a sequential process that begins with the warm/cool phase of the Pacific QDO and ultimately affects the GSL elevation, through modulations of the transition-phase teleconnection of the Pacific QDO. In this study we first examined this hypothesis through statistics and second, analyzed the hydrological cycle over the Great Basin in the quasi-decadal time scale. Datasets and methodology are introduced in section 2. Circulation pattern and the hydrological cycle analysis are presented in section 3. In Section 4 , tree-ring constructed proxy precipitation was used to analyze the long-term precipitation variations. Section 5 provides a summary and suggestions for future research.

\section{Data and methodology}

\section{a. Data and analysis domain}

Gridded data used here included the version-2 Kaplan Extended SST at a $5^{\circ}$ resolution (1900-2007; Kaplan et al. 1998), the Met Office Hadley Centre's observed mean sea level pressure version 2 (HadSLP2) dataset on a $5^{\circ}$ grid (1900-2004; Allan and Ansell 2006), the National Centers for Environmental Prediction-National Center for Atmospheric Research (NCEP-NCAR global reanalysis at a $2.5^{\circ}$ resolution (1948-2007; Kalnay et al. 1996) for the meteorological variables, the gaugebased monthly precipitation data at a $0.5^{\circ}$ resolution (1900-2006; Legates and Willmott 1990), and the Palmer drought severity index (PDSI) at a $25^{\circ}$ resolution (19482007; Dai et al. 2004). These gridded datasets were provided by the National Oceanic and Atmospheric Administration/Office of Oceanic and Atmospheric Research/Earth Systems Research Laboratory Physical Sciences Division (NOAA/OAR/ESRL PSD), Boulder, Colorado (see online at http://www.cdc.noaa.gov). The hydrological drainage basin and the watershed of the GSL are approximately within nine grid points of the NCEPNCAR global reanalysis that covers the domain of (37.5 $\left.42.5^{\circ} \mathrm{N}, 115^{\circ}-110^{\circ} \mathrm{W}\right)$, as shown in Fig. 2, which are referred to as the Great Basin hereafter. We note that part of the Snake River Valley (northwest) and the Canyonlands region (southeast) covered by this grid domain do not belong to the GSL watershed. Nevertheless, previous studies (e.g., Cayan and Roads 1984; WGJH) showed that the low-frequency precipitation variation in the Great Basin is at the regional scale and considered uniform in the central intermountain region.

Lake level (elevation) of the GSL was obtained from the U.S. Geological Survey (USGS; see online at http:// waterdata.usgs.gov/nwis). This study used the post-1900 records of the GSL level measured at Boat Harbor located southwest of the GSL. In the hydrological cycle analysis covered in section 3c, the GSL elevation was converted to lake volume using the elevation-volume relationships developed by Sangoyomi (1993) from a second-order polynomial fitting. Streamflow into the GSL is measured by three stations at the outlets of the three major rivers, which are Bear River (USGS 10126000), Weber River (USGS 10141000), and Jordan River (USGS 10171000). Their location and the corresponding number are identified in Fig. 2 as triangles. These three rivers contribute to the majority of the water drainage of the GSL (Hassibe 1991; LM95). (The monthly streamflow data were obtained online from the USGS at http://waterdata. usgs.gov/nwis/sw.)

Gauge precipitation is measured by the National Weather Service Cooperative Observer Program (COOP) stations. The COOP observations, collected by the National Climate Data Center, are archived at the Utah Climate Center in Logan, Utah (see online at http:// climate.usu.edu). Within the domain outlined in Fig. 2, active stations that provide precipitation records longer than $100 \mathrm{yr}$ with over $90 \%$ of valid observations (Moller and Gillies 2008) were averaged to represent the precipitation in the GSL watershed. The majority of these stations are distributed along the Wasatch Mountains east of the Great Basin in which most of the precipitation is received (e.g., Leung et al. 2003). In the text that follows, the term precipitation refers to station precipitation averaged in this domain, unless mentioned otherwise.

\section{b. Water vapor budget equation}

The hydrology of the Great Basin can be studied in terms of the atmospheric water vapor budget:

$$
\frac{\partial W}{\partial t}+\nabla \cdot \mathbf{Q}=E-P,
$$

where $W, P, E$, and $\mathbf{Q}$ are, respectively, precipitable water, precipitation, evaporation, and vertically integrated water vapor flux $\left[\mathbf{Q}=(1 / g) \int_{0}^{p_{s}} q \mathbf{V} d p\right.$, where $q$ is the specific humidity]. Because a direct observation of evaporation was not available, $E$ was obtained as a residual (Rasmusson 1967). Over the analysis domain, $E$ represents both evaporation (over the lake) and evapotranspiration (over the land). Based on Peixoto and Oort (1992) and considering a generalized water balance for a closed-basin lake by Shanahan et al. (2007), the change in the lake volume $(\Delta V)$ can be expressed as

$$
\Delta V=P+R_{0}-E-D,
$$




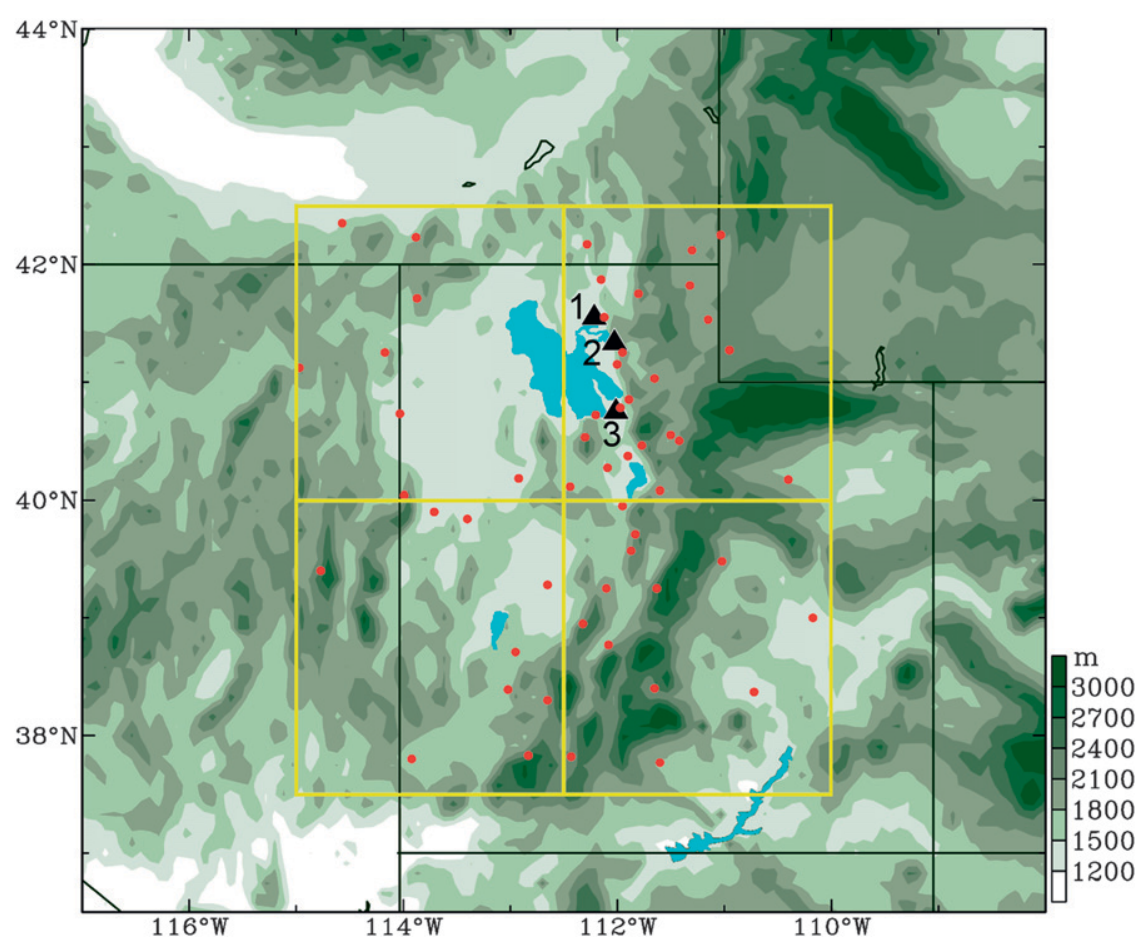

FIG. 2. Terrain (green shadings) and the Great Salt Lake (large blue area) superimposed with the mesh of nine grid points of the NCEP-NCAR reanalysis (yellow lines), COOP stations for precipitation (red dots), and three river-outlet stations for streamflow along the east lake shore (black triangles). The lower elevation area surrounded by the grid mesh is referred to as the Great Basin.

where $R_{0}$ is the runoff from the surrounding catchment area and $D$ is the discharge from the basin. Accordingly, the connection between the terrestrial and atmospheric branches of the hydrological cycle can be written as

$$
\frac{\partial W}{\partial t}+\nabla \cdot \mathbf{Q}=R_{0}-\Delta V
$$

where $D$ is neglected as the Great Basin is a closed basin the discharge term is insignificant. Streamflow is mainly accumulated from the three river outlets along the east shore of the GSL (Fig. 2). Note that $P$ in Eq. (1) includes precipitation both directly over the GSL and the rest of the GSL watershed, but the former is not included in the COOP data.

Applying the Helmholtz theory, Chen (1985) decomposed the water vapor flux into the rotational component from the moisture flux streamfunction and, the divergent component $\left(\mathbf{Q}_{D}\right)$ from the moisture flux potential $\left[\chi_{Q}=\nabla^{-2}\left(\nabla \cdot \mathbf{Q}_{D}\right)\right]$. Thus, Eq. (1) can next be rewritten as

$$
\frac{\partial W}{\partial t}+\nabla^{2} \chi_{Q}=E-P
$$

The divergent water vapor flux $\left(\mathbf{Q}_{D}\right)$ can further be divided into the stationary $\left(\bar{Q}_{D}\right)$ and transient $\left(Q_{D}^{\prime}\right)$ components. In the midlatitudes, $Q_{D}^{\prime}$ contributes significantly to precipitation (Smirnov and Moore 1999; Yoon and Chen 2006). A 2-8-day bandwidth (Blackmon 1976) was adopted to extract the transient component from the water vapor flux using the Butterworth bandpass filter on the daily NCEP-NCAR reanalyses, following Yoon and Chen (2006). Equation (3) is then expanded to

$$
\frac{\partial W}{\partial t}+\nabla^{2} \bar{\chi}_{Q}+\nabla^{2} \chi_{Q}^{\prime}=E-P
$$

where $\bar{\chi}_{Q}$ is the stationary component and $\chi_{Q}^{\prime}$ the transient component of moisture flux potential.

\section{The quasi-decadal variability}

a. The 12-yr cycle

Power spectral analyses of the monthly unfiltered $\Delta$ SST(Niño-4), the GSL elevation, and the precipitation are given in Figs. 3a-c, respectively, based on a global wavelet power spectrum (Morlet wavelet; Torrence and 

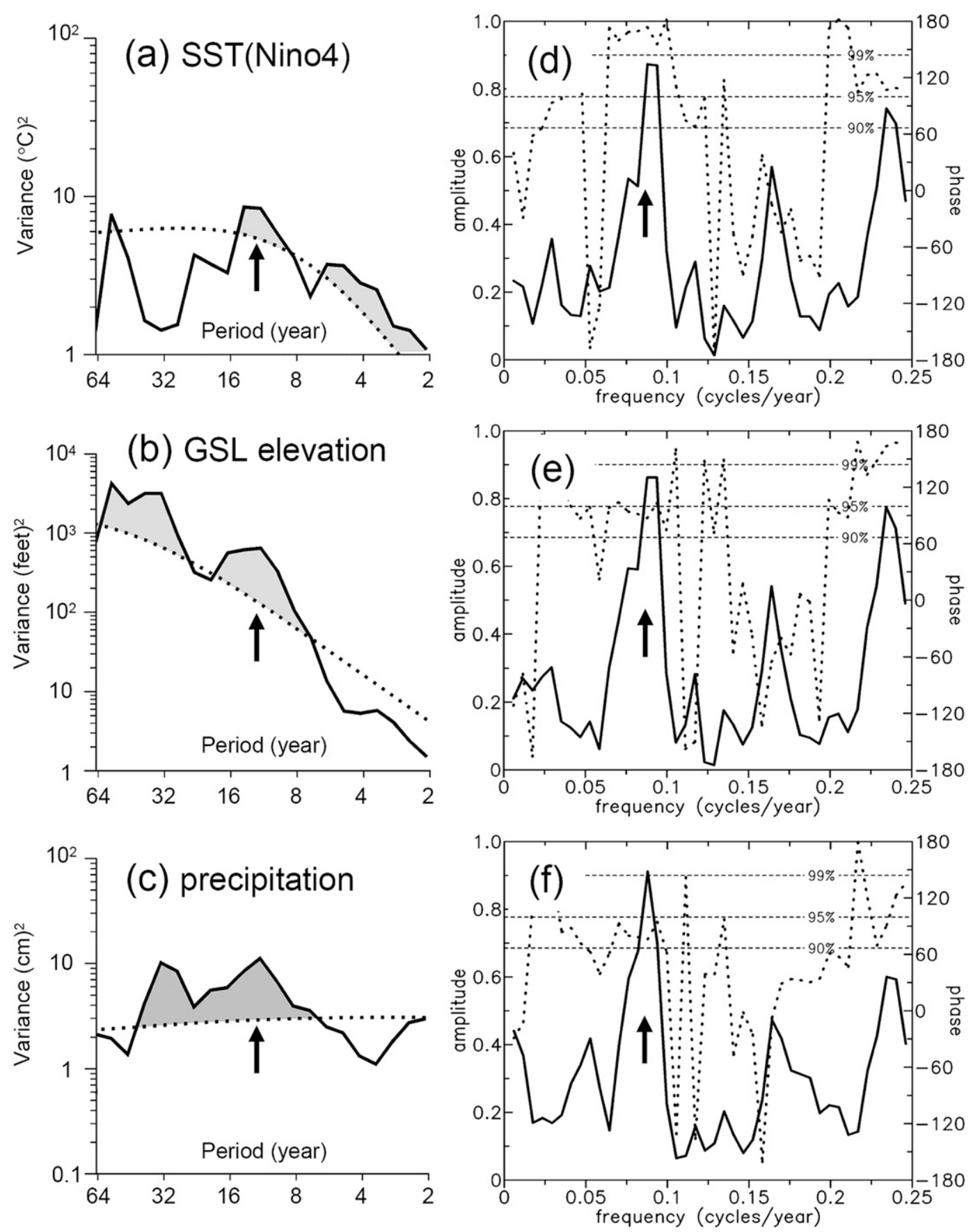

FIG. 3. The global wavelet power spectrum of monthly unfiltered (a) $\Delta$ SST(Niño-4), (b) GSL elevation, and (c) precipitation from 1900 to 2007, and the MTM coherence (solid curve) and phase (dotted curve) between $\Delta$ SST(Niño-4) and (d) the GSL elevation, (e) the GSL elevation tendency, and (f) the precipitation using three $2 \pi$ tapers. Dotted lines in (a)-(c) indicate the $99 \%$ significance level determined by a red-noise (autoregressive lag 1 ) background spectrum. The dashed horizontal lines are the (d) $90 \%$, (e) $95 \%$, and (f) $99 \%$ confidence limits for the coherence amplitude. Note that the phase lags of $180^{\circ}$ and $-180^{\circ}$ are the same. The phase difference at $0.075<f<0.1$ in (e) and (f) has $\Delta$ SST(Niño-4) leading the GSL elevation tendency and the precipitation, respectively. 
Compo 1998). All three variables show significant signals between 10 and $15 \mathrm{yr}$ (indicated by arrows), with a marked 35-50-yr mode in the GSL elevation (Fig. 3b). Signals between 2 and $6 \mathrm{yr}$ in $\Delta$ SST(Niño-4) reflect the typical quasi-biennial and interannual ENSO frequency (e.g., Philander 1990; Keppenne and Ghil 1992). On the other hand, the 2-6-yr signals are not evident in the GSL elevation and are less significant in the precipitation. Although LM95 and subsequent studies have observed interannual ENSO signals in the precipitation and the streamflow in the Great Basin as well as the GSL volume change, a large closed-basin lake such as the GSL integrates the precipitation anomalies while the integration reshapes the spectrum in lake level fluctuations and enhances it with lower frequencies than was in the precipitation (LM95), as was described by Hasselmann (1976) and is noted in Fig. 3b.

To examine the apparent association between $\Delta S S T(N i n ̃ o-4)$ and the GSL elevation as revealed from Fig. 1, the multitaper method (MTM) of spectral/ coherence analysis was performed on both unfiltered time series over the period 1900-2007. The MTM spectral/ coherence analysis provides an optimally low-variance, high-resolution spectral estimate for the two time series (Mann and Park 1996) and has been used to investigate the association of the GSL elevation/volume change with various hydrological variables (LM95; Mann et al. 1995; Moon and Lall 1996). As shown in Fig. 3d, a high degree of coherence between the GSL elevation and $\Delta$ SST(Niño-4) appears in the 10-15-yr frequency. This quasi-decadal coherence, peaking at $11.8 \mathrm{yr}$, is significant at the $95 \%$ confidence level with a near $180^{\circ}$ phase difference, supporting the out-of-phase relationship as was seen in Fig. 1.

The MTM coherence between $\Delta$ SST(Niño-4) and the monthly tendency of the GSL elevation (Fig. 3e) resembles Fig. 3d, except that the phase in the 10-15-yr frequency is now $90^{\circ}$. Significant quasi-decadal spectrums and $90^{\circ}$ phase differences are also found between $\Delta \mathrm{SST}(\mathrm{Niño}-4)$ and the precipitation in Fig. $3 \mathrm{f}$ with the peak coherence amplitude exceeding the $99 \%$ confidence level. These results indicate that the Pacific QDO leads both the precipitation and the GSL elevation tendency by a quarter-phase, confirming the quadraturephase modulation of the Pacific QDO on the intermountain rainfall as was reported in WGJH using available data that covered the most recent 50 yr. Because the GSL elevation tendency follows the precipitation and both lead the GSL elevation by a quarter-phase (LM95), Figs. 3d-f suggest that the GSL elevation lags $\Delta$ SST(Niño-4) by a half-phase $\left(180^{\circ}\right)$ amounting to about $6 \mathrm{yr}$. The results in Fig. 3 also provide a statistical verification of our hypothesis.

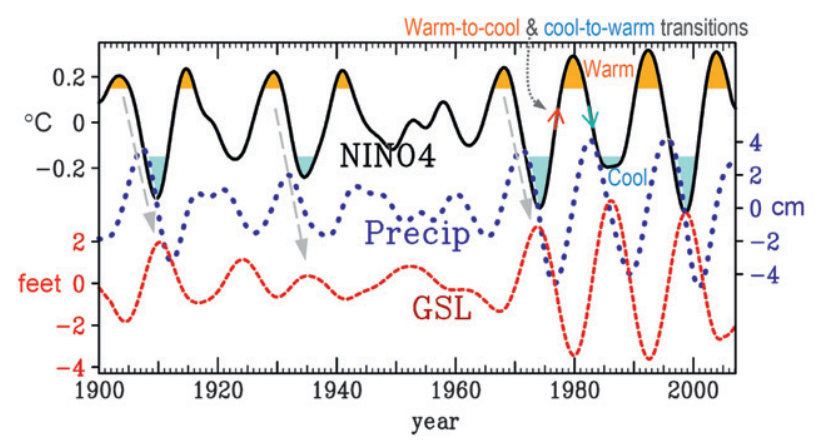

FIG. 4. Time series of bandpassed $\Delta$ SST(Niño-4) (black solid curve), precipitation in the Great Basin (blue dotted curve), and the GSL elevation (red dashed curve) from 1900 to 2007 using the HW filter with the 10-15-yr frequency. Orange (cyan) shadings in $\Delta$ SST(Niño-4) indicate years when $\Delta$ SST is above (below) the 0.8 standard deviation from the mean. These years were used for the composite analysis in Fig. 9. Gray dashed arrows describe the evolution from $\Delta S S T$ (Niño-4) to the precipitation and then to the GSL elevation with a time lag. The phasing of the Pacific QDO is explained with the $\Delta \mathrm{SST}(\mathrm{Niño}-4)$ index.

To substantiate the implications made from Fig. 3, monthly time series of $\Delta \mathrm{SST}$ (Niño-4), the precipitation, and the GSL elevation were filtered with the 10-15-yr frequency band and are shown in Fig. 4. The bandpass was carried out by the Hamming-windowed (HW) filter (Hamming 1998), which is obtained by windowing and consists of smearing the ideal filter response with a lag window (Oppenheim and Schafer 1999). The HW filter has been shown and is used as a better filter for shortlength time series, as it leads to a good attenuation of the spectral power outside the passband and allows nearcomplete removal of undesired frequency components (Iacobucci and Noullez 2005). Using the HW filter, one is able to preserve the edge of the time series and obtain the maximum degree of freedom of the QDO in the limited observation period. The major phases of a Pacific QDO revolution comprising the warm, cool, rising, and falling transition phases are illustrated with the bandpassed $\Delta$ SST(Niño-4) in Fig. 4.

The time series of $\Delta$ SST(Niño-4), precipitation, and GSL elevation reveal two approximate 40-yr periods (1900-45 and 1960-2007) with pronounced quasi-decadal variability separated by an inactive period between 1945 and 1960. As previously mentioned, the evolution of these three variables are "directional"- -by this we mean that the GSL elevation peaks $3 \mathrm{yr}$ after the precipitation maximum, which occurs 3 yr after a warm year of QDO in $\Delta$ SST(Niño-4) - as illustrated in Fig. 4 by dashed light gray arrows. The process for the GSL elevation to respond to $\Delta$ SST(Niño-4) amounts to about $6 \mathrm{yr}$, equivalent to a half-phase of the $\sim 12$-yr frequency, and forms a reverse coherence between them. Note that the "onset" 


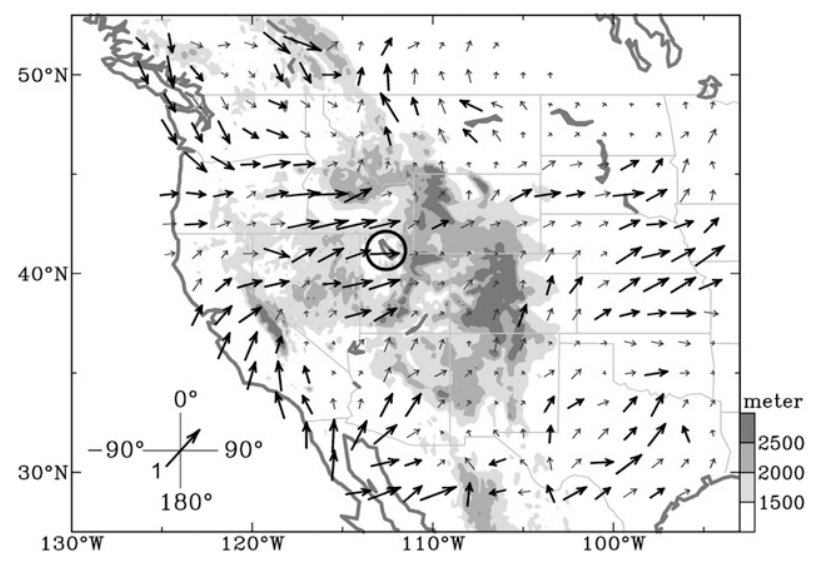

FIG. 5. Peak MTM coherence amplitudes (vector length) and average phase differences (vector direction) between monthly unfiltered $\Delta$ SST(Niño-4) and the gridded precipitation (Legates and Willmott 1990) in the $10-15$-yr frequency, plotted every $1.5^{\circ}$. The unit vector and the phases are explained in the lower left. Bold vectors represent coherence amplitudes above the $90 \%$ confidence level. A nine-point smoothing was applied on the vectors. The terrain is superimposed as shaded areas. The GSL is indicated by an open circle.

of the recent quasi-decadal episode began around 1965 with an increase in the $\Delta$ SST(Niño-4) amplitude peaking in 1968 , which propagated to precipitation peaking in 1971 and then to the GSL elevation peaking in 1974. These same processes continue until the present. The quasi-decadal signals of the three variables are noticeably weaker during the earlier QDO episode (1900-45), but their sequential evolutions as in the 1965-2007 period are quite discernable. The amplitude fluctuations of the QDO in these variables in different periods of time suggest that the QDO may well be modulated by other lower-frequency modes. This will be discussed further in section 4

\section{b. Precipitation and SST patterns}

The MTM coherence and phase between $\Delta$ SST(Niño-4) and precipitation were recomputed using gridded precipitation data (Legates and Willmott 1990) in order to examine the spatial distribution across the western United States, which are shown in Fig. 5. The analysis reveals three regions in the western United States with significant MTM coherence (with different phases): the Pacific Northwest $\left(150^{\circ}-180^{\circ}\right)$, the Great Basin $\left(\sim 90^{\circ}\right)$, and the Southwest $\left(0^{\circ}-30^{\circ}\right)$. While the near in-phase/ out-of-phase relationship between the Pacific QDO and precipitation in the southwest/northeast United States is consistent with the known north-south precipitation pattern associated with ENSO and the PDO (e.g., Gershunov and Barnett 1998; Jin et al. 2006), the central intermountain region featuring the marked, yet $90^{\circ}$ phase-shifted coherence between the Pacific QDO and the precipitation was not previously documented. Large amplitudes of the $90^{\circ}$ phase coherence appear confined to an area west of the western edge of the Rocky Mountains (covering part of Oregon, Nevada, Idaho, and Utah). The topographic confinement implies that the circulation pattern linking to this phenomenon involves westerly anomalies interacting with the mountain ranges east of the Great Basin. This echoes the observation by WGJH that the precipitation QDO in that region varies consistently with the jet stream fluctuation. The circulation aspect of this feature is discussed later in section $3 \mathrm{~d}$.

The SST patterns associated with the Pacific QDO and the GSL elevation were examined through onepoint correlation maps between the bandpassed Kaplan SST ( $\widetilde{\mathrm{SST}}$ ) and the bandpassed $\Delta$ SST(Niño-4) with different time lags, using the HW filter with the 10-15-yr frequency. The instantaneous correlation map (Fig. 6a) depicts an ENSO-like, warm-phase Pacific QDO pattern with a broad, positive area in the central Pacific and a narrow, negative area in the midlatitude North Pacific, consistent with that shown in Allan (2000). When correlating SST with a 3-yr lead in $\Delta$ SST(Niño-4), the major warming areas shift to the two sides of tropical Pacific (Fig. 6b). This SST pattern resembles that during the warm-to-cool transition of the Pacific QDO with relatively strong warming in the Niño- $1+2$ region $\left(0^{\circ}-10^{\circ} \mathrm{S}\right.$, $80^{\circ}-90^{\circ} \mathrm{W}$; Tourre et al. 2001; Wang et al. 2010). The correlation between $\widetilde{\text { SST }}$ and the bandpassed precipitation in the Great Basin, with a 3-yr lag in precipitation (Fig. 6c), reveals a warm-phase Pacific QDO pattern as in Fig. 6a. The instantaneous correlation between SST and the precipitation (Fig. 6d) delivers a SST pattern similar to the transition-phase Pacific QDO in Fig. 6b. With a 3-yr lead in precipitation, Fig. 6e depicts a coolphase Pacific QDO pattern opposite to Fig. 6a.

When correlating SST with the GSL elevation without time lags, the SST pattern shows a cool-phase Pacific QDO (Fig. 6h), consistent with their out-of-phase relationship. With a 3-yr lag in the GSL elevation, the SST pattern (Fig. 6g) resembles Figs. 6b,d showing weak central tropical Pacific features. With a 6-yr lag in the GSL elevation Fig. 6f "restores" the warm-phase Pacific QDO pattern. Because of the limited degrees of freedom in the observational period (1900-2007), the correlation coefficients in Figs. 6b,d,g are mostly under the 95\% significance level. Nevertheless, their consistent distribution and strong resemblance with the SST pattern formed during the transition phases of the Pacific QDO (Tourre et al. 2001; Wang et al. 2010) help justify the association of the GSL elevation and precipitation with the Pacific QDO evolution. 

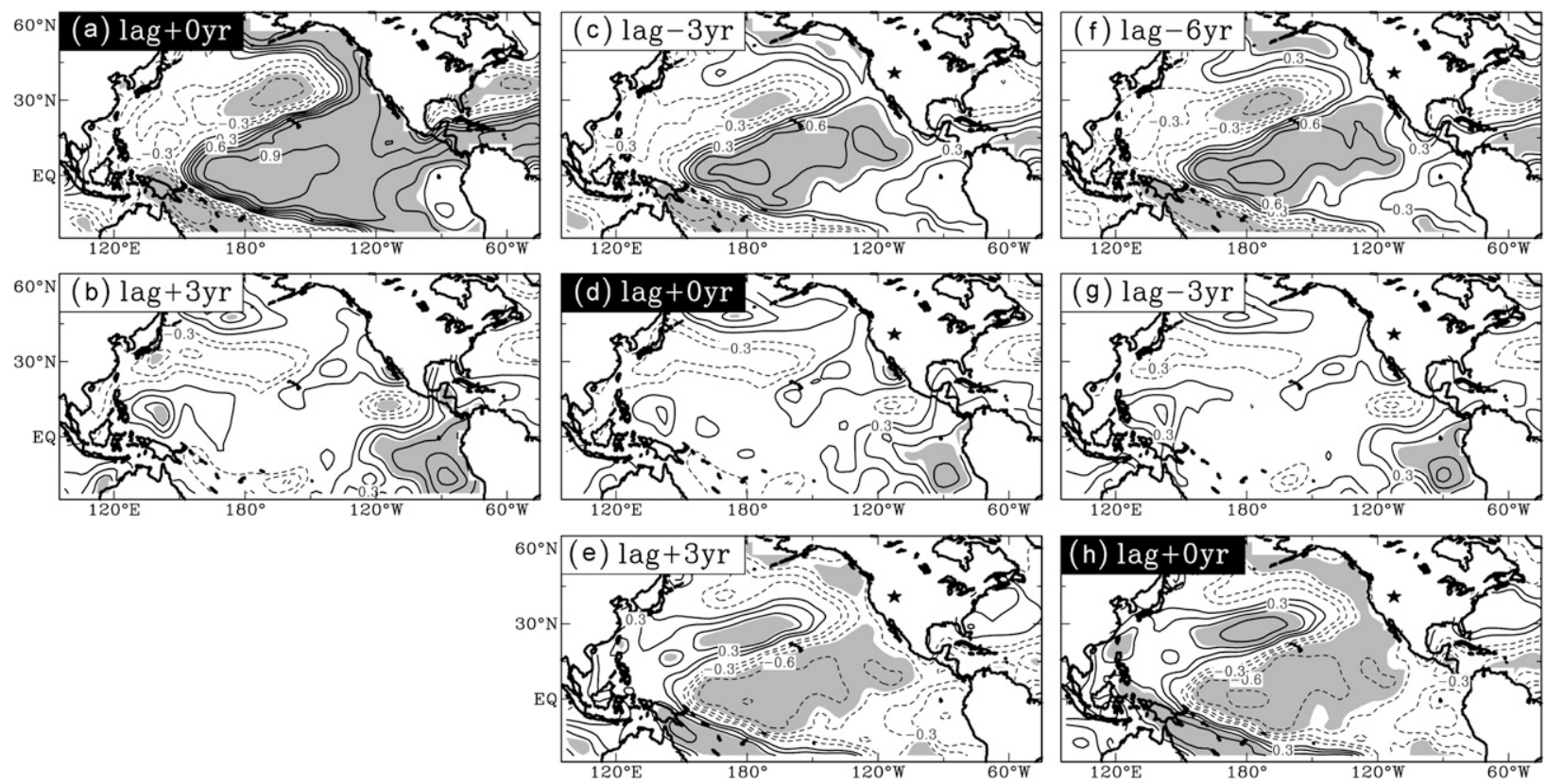

FIG. 6. Correlation maps between the Kaplan SST and (a) $\Delta$ SST(Niño-4) without time lag and (b) with a 3-yr lead in $\Delta$ SST(Niño-4), precipitation in the Great Basin with (c) a 3-yr lag in precipitation and (d) without time lag, and (e) with a 3-yr lead in precipitation, and the GSL elevation with (f) a 6-yr lag, (g) a 3-yr lag, and (h) without a time lag in the GSL elevation. All variables were bandpassed with a 1015-yr frequency by the HW filter, while the data length spans 1900-2007. The subtitle of correlation maps without time lag is presented differently. Values above the $95 \%$ confidence level $(\mathrm{df}=9)$ are shaded. The contour interval is 0.15 with the 0 contours omitted. The GSL is marked by a star in (c)-(h).

\section{c. Water vapor budget analysis}

The atmospheric processes leading to the precipitation and the GSL volume change was examined through the water vapor budget analysis of Eqs. (1) and (2). The atmospheric variables (i.e., $\boldsymbol{\nabla} \cdot \mathbf{Q}$ and $\partial W / \partial t$ ) obtained from the NCEP-NCAR reanalysis were only available from 1948. Thus, monthly hydrological variables were averaged at/within the nine grid points outlined in Fig. 2 for the time period of 1948-2007. All variables were bandpassed using the HW filter with the 10-15-yr frequency (Fig. 7). The original time series of $P, \nabla \cdot \mathbf{Q}$, $\partial W / \partial t, R_{0}$, and the PDSI were lowpassed by 18 months to eliminate the seasonal cycle and are superimposed in Fig. 7 (gray thin lines) for comparison. It should be noted that, given the variety of data sources, an exact balance between Eqs. (1) and (2) is not possible. The analysis here stresses the time variation and temporal coherence among these hydrological variables. The power spectrum of all observed variables in Fig. 7 is significant in the $10-15-y r$ frequency at the $95 \%$ confidence level (not shown).

The time series of precipitation and $\boldsymbol{\nabla} \cdot \mathbf{Q}$ (Figs. 7a,b) are very coherent, even though they come from independent datasets. This suggests that the precipitation variation is largely controlled by the convergence and divergence of the moisture flux over the Great Basin. The storage term ( $\partial W / \partial t$; Fig. 7c) is weak, as would be expected theoretically (Peixoto and Oort 1992). The amplitude of $\boldsymbol{\nabla} \cdot \mathbf{Q}$ is about $20 \%$ larger than the precipitation, while most of this amplitude difference is transferred to the residual term $E$ (Fig. 7d). Here the magnitude of $E$ may be underestimated because the residual evaporation by definition carries the sum of errors and is usually smaller than that observed (Roads et al. 1994). Nevertheless, the strong coherence of the quasi-decadal variations revealed over Figs. 7a-d indicates that the precipitation QDO in the Great Basin must be balanced with moisture flux convergence/divergence and evaporation in the same frequency.

Streamflow into the GSL $\left(R_{0} ;\right.$ Fig. $\left.7 \mathrm{e}\right)$ depicts a clear QDO showing similar phase and amplitude with the precipitation. The variation of $R_{0}$ also closely follows $\nabla \cdot \mathbf{Q}$, especially after 1965 . The coherence between $R_{0}$ and $\boldsymbol{\nabla} \cdot \mathbf{Q}$ was verified by the estimated GSL volume change [ $\Delta V$ as a residual from Eq. (2); thick line] in Fig. $7 \mathrm{f}$, because $\Delta V$ is very close to the observed GSL volume change (shaded line). Note that $\Delta V$ in Eq. (2) has a minus sign that is not included in Fig. 7f. Regardless of any data bias, the small difference between the residual and observed $\Delta V$ is likely due to the presence of 


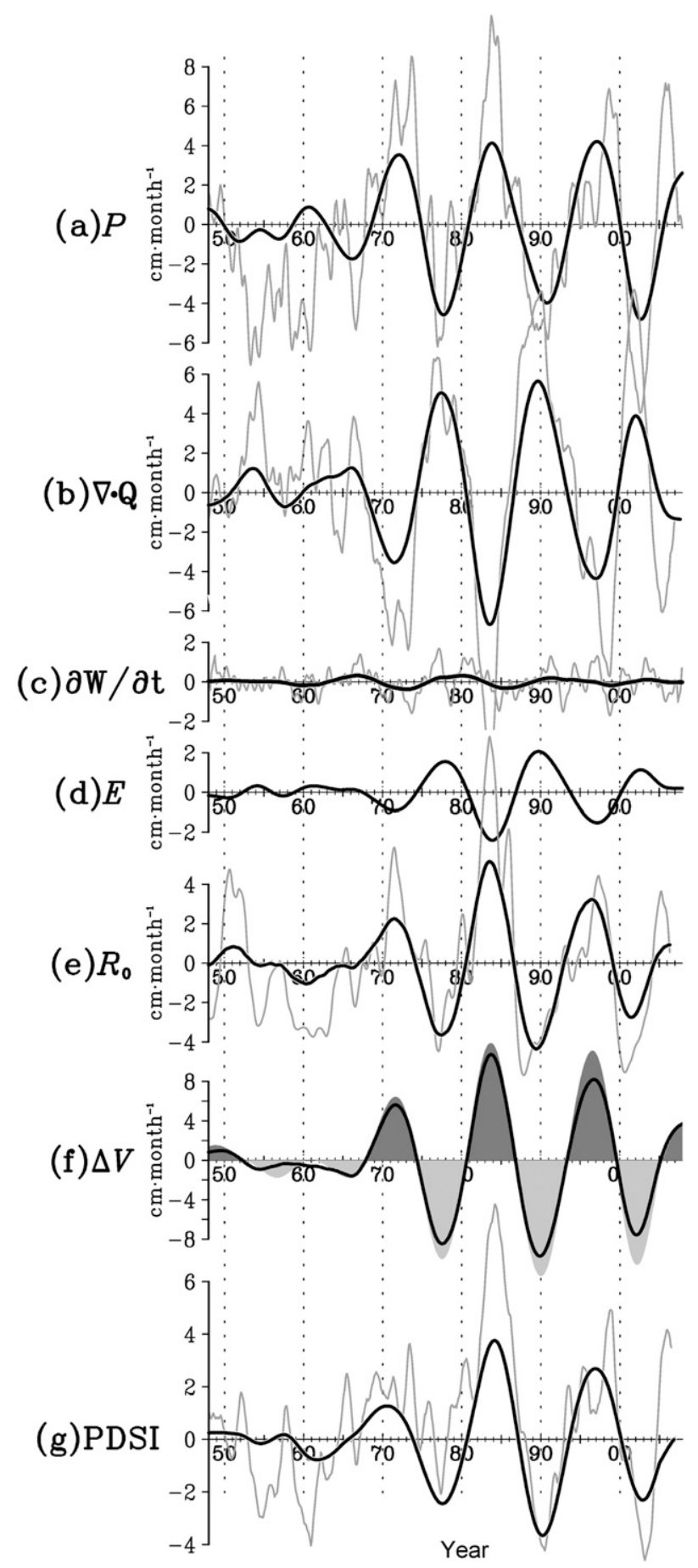

FIG. 7. Bandpassed time series of (a) precipitation, (b) water vapor flux divergence, (c) rate of change of precipitable water, (d) evaporation, (e) runoff, (f) GSL volume change as a residual from Eq. (2) (solid curve) superimposed with the observed GSL volume change (shaded curve), and (g) the PDSI in the Great Basin. The original time series lowpassed by 18 months are superimposed as thin gray lines. groundwater and the neglected discharge. Combining Figs. 7a-f indicates that, at the quasi-decadal time scale, the GSL volume change is profoundly modulated by the moisture flux convergence/divergence over the Great Basin.

One of the quasi-decadal events coincides with the record-high lake level of the GSL that occurred in 1986 following the abnormally wet winters over $1983-85$. To cope with lake water floods under such intense precipitation events, the state of Utah built the West Desert Pumping Project, which was designed to drain any excess of water from the GSL. Over $1986-89,3.4 \mathrm{~km}^{3}$ of lake water was pumped out, resulting in a noteworthy decline of one-third of the lake level during the 1987-90 period. The other two-thirds in this GSL decline were explained through natural processes (Hassibe 1991). The QDO in PDSI (Fig. 7g) mirrors the QDO in GSL volume change during this event, because any abrupt downtrend (uptrend) of the GSL is often coupled with severe droughts (wet periods) (King et al. 2007). According to the Köppen climate classification, the intermountain region is an arid/semiarid area where mean evaporation is generally greater than mean precipitation. This leads to slower soil recharge processes than those experienced in different climates and so, delays runoff generation and water supplies to the GSL and in doing so, may contribute to the multiple-year lag of the GSL elevation behind the precipitation as noted in LM95 and Mann et al. (1995). The strong coherence between the GSL volume change and the drought conditions (Figs. 7f,g) also supports the relatively slow soil recharge process.

Precipitation in the intermountain region is mainly produced by transient synoptic activity such as cyclone waves and frontal passages interacting with orography (Ely et al. 1994; Harnack et al. 1998; Shafer and Steenburgh 2008). Thus, the transient component of water vapor flux divergence $\left(\boldsymbol{\nabla} \cdot \mathbf{Q}_{D}^{\prime}\right)$ was extracted to examine the role of transient synoptic activity on the hydrological cycle, following Eq. (4). As displayed in Fig. 8a, the QDO signal is very pronounced in $\boldsymbol{\nabla} \cdot \mathbf{Q}_{D}^{\prime}$, while the amplitude of $\boldsymbol{\nabla} \cdot \mathbf{Q}_{D}^{\prime}$ is about $20 \%$ smaller than the total water vapor flux divergence (Fig. 7b), but is now closer to the precipitation (Fig. 7a). By replacing $\boldsymbol{\nabla} \cdot \mathbf{Q}$ with $\boldsymbol{\nabla} \cdot \mathbf{Q}_{D}^{\prime}$ in Eq. (1), the residual evaporation (Fig. 8b) becomes very small. This indicates that, at the quasi-decadal time scale, precipitation is nearly balanced by $\boldsymbol{\nabla} \cdot \mathbf{Q}_{D}^{\prime}$ over the Great Basin, thus approximating Eq. (4) to

$$
\nabla \cdot \mathbf{Q}_{D}^{\prime}=\nabla^{2} \chi_{Q}^{\prime} \approx P .
$$

Equation (5) shows that water vapor flux convergence induced by synoptic transient activity is the primary 


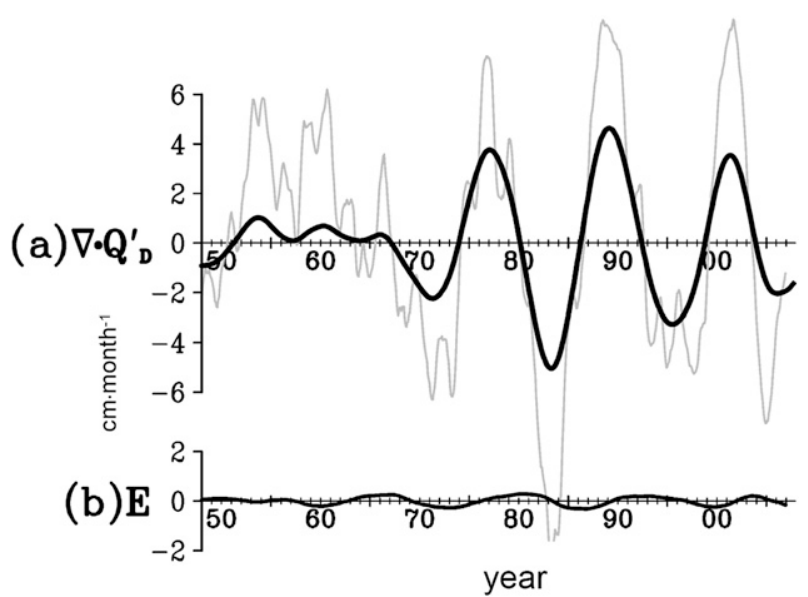

FIG. 8. (a) As in Fig. 7b, but for the transient component of water vapor flux divergence, and (b) evaporation as a residual from Eq. (1) with $\nabla \cdot \mathbf{Q}_{D}^{\prime}$ as in (a).

contributor of precipitation over the Great Basin. Therefore, any change in the transient moisture flux potential $\left(\chi_{Q}^{\prime}\right)$ will directly impact the precipitation. Thus, Eq. (5) enables us to examine the atmospheric circulation pattern directly involved in the hydrological process of the GSL in the form of $\chi_{Q}^{\prime}$. This offers an advantage over the analysis of wind fields or geopotential height in which any suggested links must be inferred.

\section{d. Responses in precipitation and the atmospheric circulation}

Decadal variations of the SST anomalies in the tropical/ North Pacific are known to induce an ENSO-like PacificNorth America (PNA; Wallace and Gutzler 1981) circulation pattern (e.g., Barlow et al. 2001) and modulate the strength and position of the Aleutian low (e.g., Mantua et al. 1997). These factors also cause the distinct northsouth pattern in precipitation across the western United States (Dettinger et al. 1998; Gershunov and Barnett 1998). To examine the circulation patterns associated with the Pacific QDO and the precipitation variation in the Great Basin, composites of gridded precipitation (Legates and Willmott 1990) and sea level pressure (SLP; HadSLP2) were made for the cold season (NovemberMarch) during the high-index and low-index years of the bandpassed $\Delta$ SST(Niño-4) as was shown in Fig. 4. The differences in the precipitation and SLP patterns between the high- and low-index composites are presented in Fig. 9a-the years used in the composites are given in the caption. The north-south precipitation pattern across the intermountain region, as well as an anomalous low pressure cell in the subtropical eastern Pacific, is typical to those associated with the warm-phase ENSO and the positive-phase PDO (cited earlier). However, the GSL lies in the transitional zone of this north-south precipitation pattern, where any positive correlations from the warm-/cool-phase Pacific QDO are more or less cancelled out by negative correlations. Using the high-/low-index years plus 3 years (36 months), the composite precipitation and SLP patterns (Fig. 9b) shift northward about $15^{\circ}$ in latitude, with the maximum amplitudes of precipitation and SLP positioned near their zero contours as in Fig. 9a. This indicates a quadrature relationship of the circulation and precipitation patterns between Figs. 9a,b corresponding to their temporally quadrature relationship (this will be additionally examined in Figs. 10 and 11). The low pressure cell is located near the Gulf of Alaska while positive precipitation anomalies now cover the GSL area (Fig. 9b). Note the marked consistency of patterns between the precipitation anomalies in Fig. 9a (Fig. 9b) and the near $0^{\circ} / 180^{\circ}$ $\left(90^{\circ}\right)$ phases in Fig. 5.

To support the association between the SLP pattern and the precipitation pattern, composites of vertically integrated water vapor flux $(Q)$ and precipitable water $(W)$, made for cases within the time period of 1948-2007 by following Figs. 9a,b, are shown in Figs. 9c,d, respectively. During the extreme phases of the Pacific QDO (Fig. 9c), the cyclonic pattern of water vapor flux corresponds well with the low pressure cell in Fig. 9a, creating high moisture content in the southwest United States while transporting moisture away from the northwest United States. In Fig. 9d which reflects the warm-to-cool transition of the Pacific QDO, the patterns of water vapor flux anomalies shift northward associated with the low-pressure cell, thereby transporting moisture from the subtropical eastern Pacific toward the western United States. Although water vapor transport is a crucial ingredient for precipitation, moisture pooling alone does not necessarily lead to precipitation. Based on Eq. (5), precipitation requires a transient mode of the moisture flux potential function $\left(\chi_{Q}^{\prime}\right)$ to occur in the right place. Thus, $\chi_{Q}^{\prime}$ was analyzed as an independent physical parameter to delineate the circulation pattern.

An empirical orthogonal function (EOF) analysis was first performed on $\chi_{Q}^{\prime}$ lowpassed by 18 months (to eliminate seasonality; not shown). The MTM coherences between $\Delta$ SST(Niño-4) and EOFs 1 and 2 of the low-passed $\chi_{Q}^{\prime}$ are significant in the 10-15-yr frequency at the $95 \%$ confidence level, with $0^{\circ}$ phase in EOF 1 (Fig. 10a) and $90^{\circ}$ phase in EOF 2 (Fig. 10b). This suggests that EOFs 1 and 2 of $\chi_{Q}^{\prime}$ are associated with the warm/cool phases and the transition phases of the Pacific QDO revolution, respectively. After applying the HW filter on $\chi_{Q}^{\prime}$ with the $10-15-y r$ frequency, EOF 1 of the bandpassed $\chi_{Q}^{\prime}$ (Fig. 10c) shows an area of moisture flux convergence 
$\triangle \mathrm{SST}(\mathrm{NINO4)}$

(High index) minus (low index)
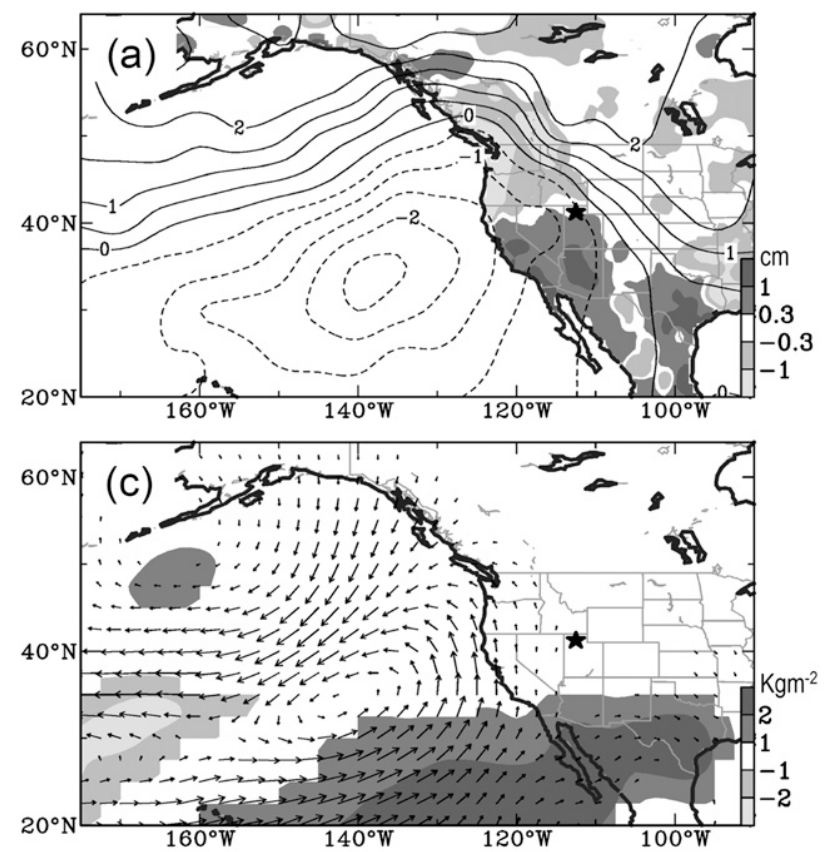

$\triangle \mathrm{SST}(\mathrm{NINO4})$

(High index +3 yrs) minus (low index +3 yrs)
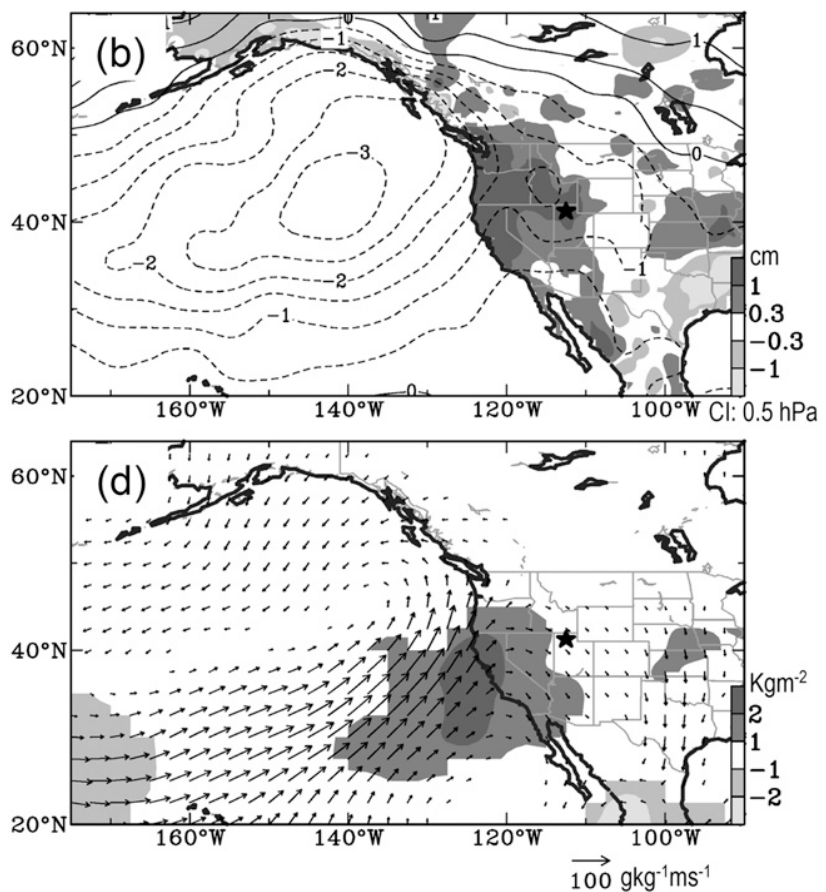

FIG. 9. (a) Differences in precipitation (shadings) and SLP (contours) between composites of high-index years (1902-04, 1914-16, 192830, 1940-42, 1967-69, 1978-81, 1991-94, and 2003-05) and low-index years (1909-11, 1923, 1934-36, 1973-75, 1985-87, and 1997-2000) during the cold season (November of the previous year to March), based on the bandpassed $\Delta$ SST(Niño-4) as shown in Fig. 4. The contour interval of SLP is $0.5 \mathrm{hPa}$ while precipitation below the $95 \%$ confidence level ( $t$ test) is omitted. (b) As in (a), but for the composites between high- and low-index years plus 3 yr. (c),(d) As in (a),(b), but for the composite water vapor flux (vectors) and precipitable water (shadings), with values under the $95 \%$ confidence level omitted. All data are unfiltered. The GSL is indicated by a star. Significance level of SLP was not performed, as it is supported by the consistent pattern of water vapor flux.

at $30^{\circ} \mathrm{N}$ in the subtropical eastern Pacific and strong moisture flux divergence near $45^{\circ} \mathrm{N}$ in the central North Pacific. Its temporal evolution (Fig. 10e) is highly correlated with the bandpassed $\Delta \mathrm{SST}(\mathrm{Niño}-4)$, indicating that this $\chi_{Q}^{\prime}$ mode is coupled with the warm/cool phases of the Pacific QDO. EOF 2 of the bandpassed $\chi_{Q}^{\prime}$ (Fig. 10d) depicts a zonally oriented band of pronounced moisture flux convergence along $40^{\circ} \mathrm{N}$ across the GSL. The temporal evolution of this mode (Fig. 10f) varies closely with the Great Basin precipitation while both are $90^{\circ}$ phase shifted from $\Delta$ SST(Niño-4). The correlation coefficients between EOF 1 and $\Delta$ SST(Niño-4) and between EOF 2 and precipitation are significant (upper left in Figs. 10e,f). Keep in mind that the EOF of $\chi_{Q}^{\prime}$ was computed independently from $\Delta$ SST(Niño-4) and the precipitation, so the coherence between them strongly suggests that precipitation in the Great Basin is linked to the variation of $\chi_{Q}^{\prime}$ associated with the transition phases of the Pacific QDO.

The upper-level circulation pattern accompanying the $\chi_{Q}^{\prime}$ anomalies was depicted through the bandpassed
200-hPa eddy streamfunction $\left(\psi_{E}\right.$; with the zonal mean removed) regressed upon the first and second normalized eigencoefficients of $\chi_{Q}^{\prime}$ as in Figs. 10e,f. The regression map of $\psi_{E}$ with EOF 1 of $\chi_{Q}^{\prime}$ reveals a classic PNA pattern (Fig. 11a) emanating from the centraleastern equatorial Pacific. When regressed with EOF 2 of $\chi_{Q}^{\prime}$, the $\psi_{E}$ pattern (Fig. 10b) delineates a distinct cyclonic cell over the Gulf of Alaska with an elongated anticyclonic cell in the subtropical eastern Pacific. This circulation dipole intensifies the westerly jet entering the intermountain region across the GSL, at the same time as this increased jet enhances synoptic transient activity (WGJH) as well as convergence of transient moisture flux (Fig. 10d). The cyclonic cell in Fig. 11b is also in good agreement with the low pressure cell in Fig. $9 \mathrm{~b}$ revealing a barotropic structure.

Wang et al. (2010) suggested that the short-wave train associated with the transition phases of the Pacific QDO may be the circulation's response to anomalous diabatic heating in the tropical western Pacific, rather than forcing sources in the central and eastern equatorial Pacific. To 

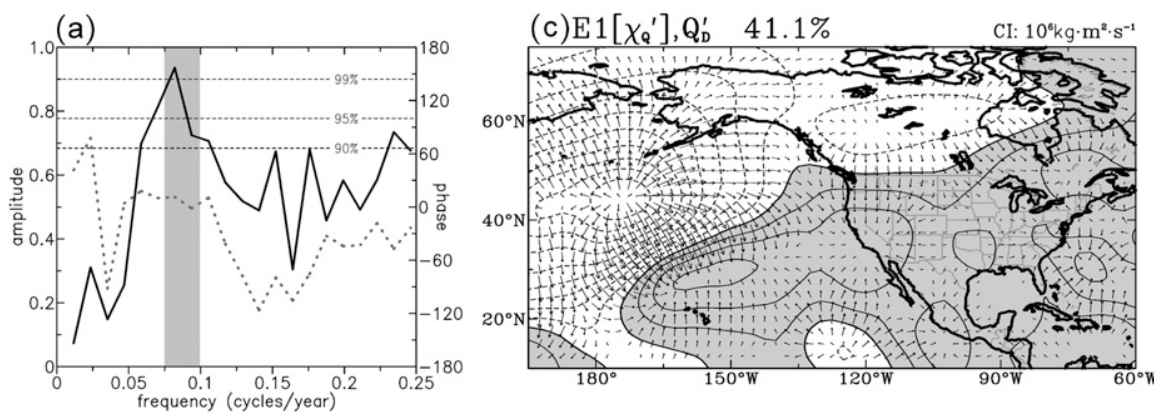

CI: $10^{6} \mathrm{~kg} \cdot \mathrm{m}^{2} \cdot \mathrm{s}^{-1}$
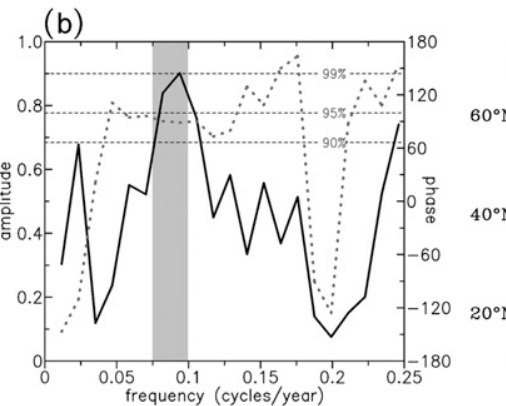

(d) $\mathrm{E} 2\left[\chi_{Q}^{\prime}\right], \mathrm{Q}_{\mathrm{D}}^{\prime} \quad 30.2 \%$
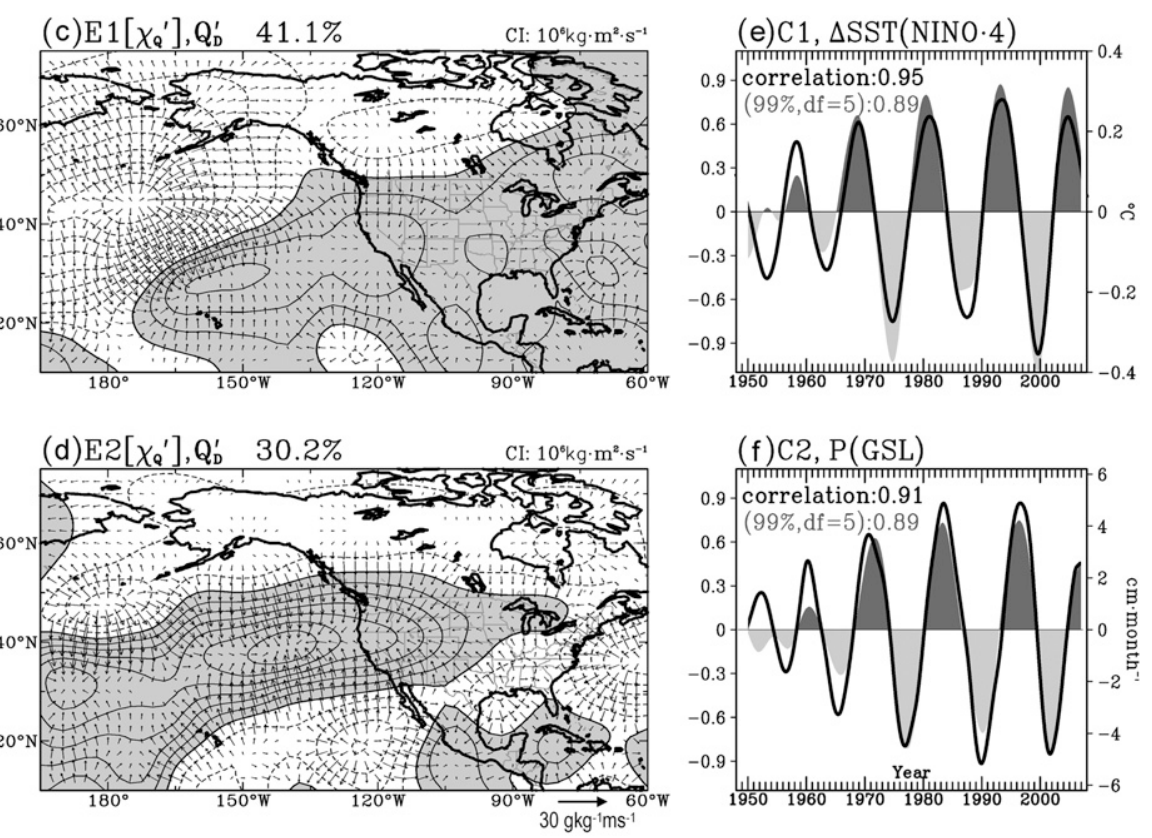

(f)C2, P(GSL)

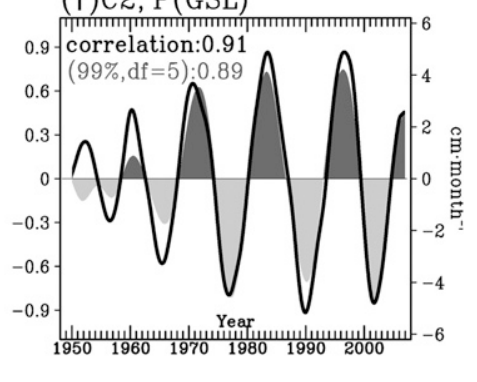

FIG. 10. MTM coherence and phase of monthly $\triangle \mathrm{SST}(\mathrm{Niño}-4)$ with (a) EOF 1 and (b) EOF 2 of the transient moisture flux potential $\left(\chi_{Q}^{\prime}\right)$ lowpassed by 18 months (to eliminate seasonality) using three $2 \pi$ tapers following Figs. $3 \mathrm{~d}-\mathrm{f}$. The phase difference at the quasidecadal frequency in (b) has $\Delta \mathrm{SST}$ (Niño-4) leading EOF 2 of $\chi_{Q}^{\prime}$ by $90^{\circ}$. (c) EOF 1 and (d) EOF 2 of the 10-15-yr bandpassed $\chi_{Q}^{\prime}$ superimposed with divergent water vapor flux (vectors). (e) and (f) Normalized eigencoefficients (solid curve) corresponding to (c) and (d) superimposed with the bandpassed (e) $\Delta \mathrm{SST}$ (Niño-4) and (f) precipitation in the Great Basin (shaded curves), with the correlation coefficients and confidence levels shown in the upper left. The GSL is marked by a star in (c) and (d).

examine this we adopted the Plumb flux (Plumb 1985) to reveal possible source regions for the stationary waves in Fig. 11. In the horizontal plane, the Plumb flux (F) may be expressed as

$$
\mathbf{F}=\left\{\frac{p}{2 a^{2} \cos \varphi}\left[\left(\frac{\partial \psi^{\prime}}{\partial \lambda}\right)^{2}-\psi^{\prime} \frac{\partial^{2} \psi^{\prime}}{\partial \lambda^{2}}\right], \quad \frac{p}{2 a^{2}}\left(\frac{\partial \psi^{\prime}}{\partial \lambda} \frac{\partial \psi^{\prime}}{\partial \varphi}-\psi^{\prime} \frac{\partial^{2} \psi^{\prime}}{\partial \lambda \partial \varphi}\right)\right\}
$$

where $\psi^{\prime}$ is the geopotential streamfunction with the zonal mean removed; $p$ is the pressure level; $a$ is the radius of the earth; and $\phi$ and $\lambda$ are latitude and longitude, respectively, as was used in Barlow et al. (2001). The Plumb flux diagnostic of stationary wave activity can capture the tropics-to-midlatitude Rossby wave propagation resulting from a tropical heating source.

The 200-hPa Plumb flux regressed with the leading EOFs of $\chi_{Q}^{\prime}$ are superimposed with the stationary eddies in Fig. 11. In the warm phases of the Pacific QDO (Fig. 11a), a flux of stationary wave activity emanates from the central tropical Pacific toward North America following the classic PNA great circle route (Karoly et al. 1989). However, during the transition phases of the Pacific QDO (Fig. 11b), the flux of stationary wave activity comes mainly from the western North Pacific with weak influx from the central tropical Pacific. This signifies the difference in source regions of the teleconnection pattern between the warm/cool phases and the transition phases of the Pacific QDO. Note that the tropicalextratropical connection is not solely reflected in the stationary waves and so, may not be fully revealed by Plumb flux analysis (Barlow et al. 2001). Wang et al. (2010) contended that the moist teleconnection mechanism (Neelin 2007), in which moist static energy is redistributed and propagated through the divergent circulation, may contribute to the tropical-extratropical teleconnection of the wave train. The results in Fig. 11 bring to light the fact that precipitation in the Great Basin is modulated by a teleconnection pattern that is distinct from the classic PNA pattern.

\section{Precipitation cycles in the preinstrumental record}

Despite the striking consistency among the quasi-decadal cycles revealed from the eclectic analysis of various 

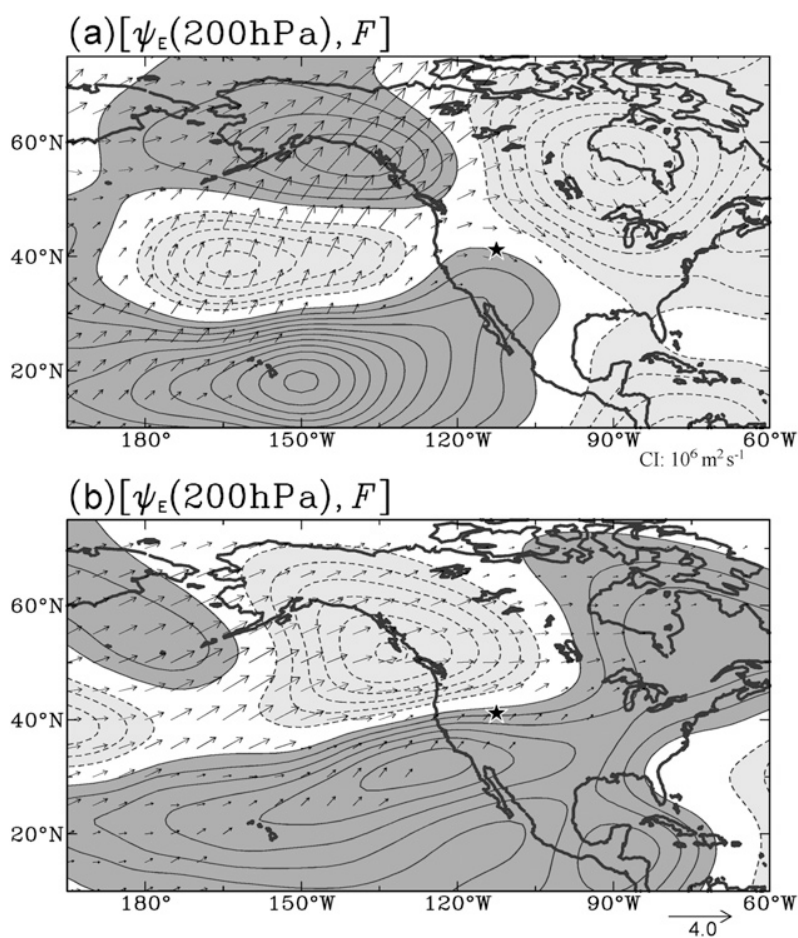

FIG. 11. Horizontal patterns of bandpassed eddy streamfunction at $200 \mathrm{hPa}$ superimposed with vectors of the horizontal stationary wave activity flux regressed upon the normalized coefficients of (a) EOF 1 and (b) EOF 2 of bandpassed $\chi_{Q}^{\prime}$ as in Figs. 10e,f. Vectors of the Plumb flux below the $90 \%$ confidence level and zero contours of the streamfunction are omitted. Positive (negative) areas of streamfunction are darkly (lightly) shaded. The GSL is indicated by a star.

hydrological variables, we take note that the short observational time period with limited QDO episodes may not represent enough degrees of freedom to have enough statistical power with perfect confidence. Instrumental precipitation data in the Great Basin only date back to the 1890 s, and the length of reliable atmospheric data is considerably shorter. Thus, proxy precipitation constructed by tree-ring chronology was used. Compiling the tree-ring records in northeastern Utah, Gray et al. (2004) constructed a 776-yr precipitation record from 1226 to 2001 . Because the area where the tree-ring samples were collected is a part of the GSL watershed, it is reasonable to examine Gray et al.'s treering proxy precipitation in order to evaluate the significance of the QDO and other low-frequency cycles revealed from the GSL elevation and instrumental precipitation data. The correlation coefficient between the tree-ring precipitation and the annual precipitation in the Great Basin from 1900 to 2001 is 0.72 . The time series of this tree-ring precipitation is shown in Fig. 12 as a gray histogram smoothed by a 6-yr lowpass filter.
The power spectrums of the unfiltered tree-ring precipitation (Fig. 12c) show three significant modes, with one covering the 150-200-yr frequency and the other two corresponding to the 35-50- and 10-15-yr cycles of the GSL elevation as was observed in Fig. 3b. The treering precipitation was then filtered by these three frequency bands using the HW filter. The precipitation QDO (thin solid line in Fig. 12a) prevails throughout the 776-yr period with varying amplitudes. The periods with large QDO amplitude seem to follow the 150-200-yr variation mode (thick solid line), as the precipitation QDO amplifies (decays) during positive (negative) phases of the 150-200-yr mode. To inspect this observation, we computed the root-mean-square (RMS) of the precipitation QDO within a 30-yr time span averaged for each year (15 yr at the two ends), which generates a new time series measuring the variability of the QDO with time (dotted line). The RMS of the QDO appears to correlate with the 150-200-yr mode with a correlation coefficient of 0.82 .

This 150-200-yr mode echoes the "secular mode" of the GSL elevation pointed out by previous studies (e.g., LM95), and its uptrend during the twentieth century coincides with the climate regime shift observed in the hydrological cycle in the Colorado River basin (Hidalgo and Dracup 2003) and the GSL volume change (Mann et al. 1995) during the 1970s. The precipitation QDO appears to amplify with the uptrend of the 150-200-yr mode during the middle twentieth century. However, the 150-200-yr mode had reached its peak around the 1990s after which it started to downtrend. It correlates with the weakening signals of QDO in most of the hydrological variables after 1990 (Fig. 7). It will be of interest to monitor if precipitation in the Great Basin continues to follow such a tendency.

The 35-50-yr variation cycle of the tree-ring precipitation (Fig. 12b) appears to be a prominent climate mode, as well, though it does not reveal an apparent association with the other two cycles. This $35-50$-yr cycle is most pronounced between 1500 and 1650 and has weakened since starting around 1650 . Regardless, the $35-50-y r$ precipitation cycle is consistent with the 35$50-y r$ cycle of the GSL elevation: since 1900, the three peaks of the 35-50-yr cycle in the GSL elevation systematically trail the $35-50-y r$ cycle of the tree-ring precipitation by a quarter-phase (Fig. 12b lower right; indicated by arrows). This again confirms the results of LM95 that the GSL volume change is highly coherent with precipitation in all frequencies. Noteworthy is the implication made from such a coupling between the GSL elevation and the precipitation cycles in that the lake level fluctuations of the GSL during the period covered by $1500-1600$ would have been about 3 times larger than 


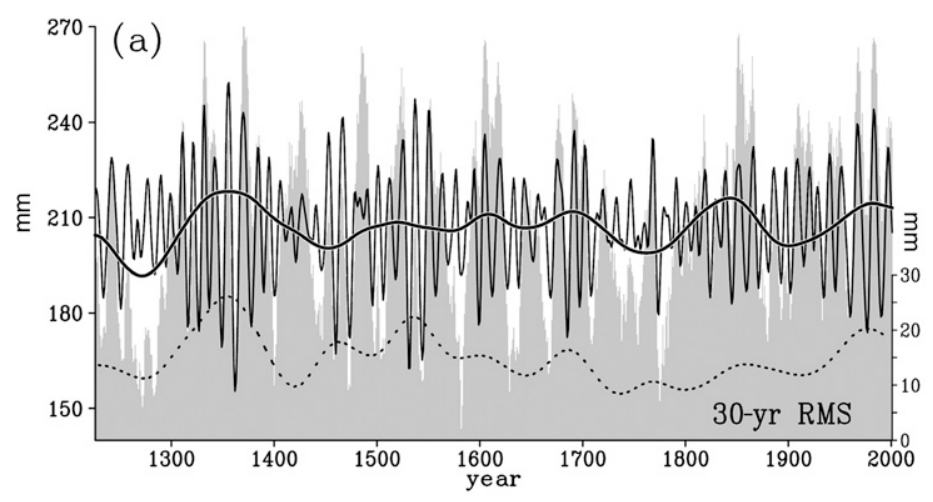

(c) Power spectrum
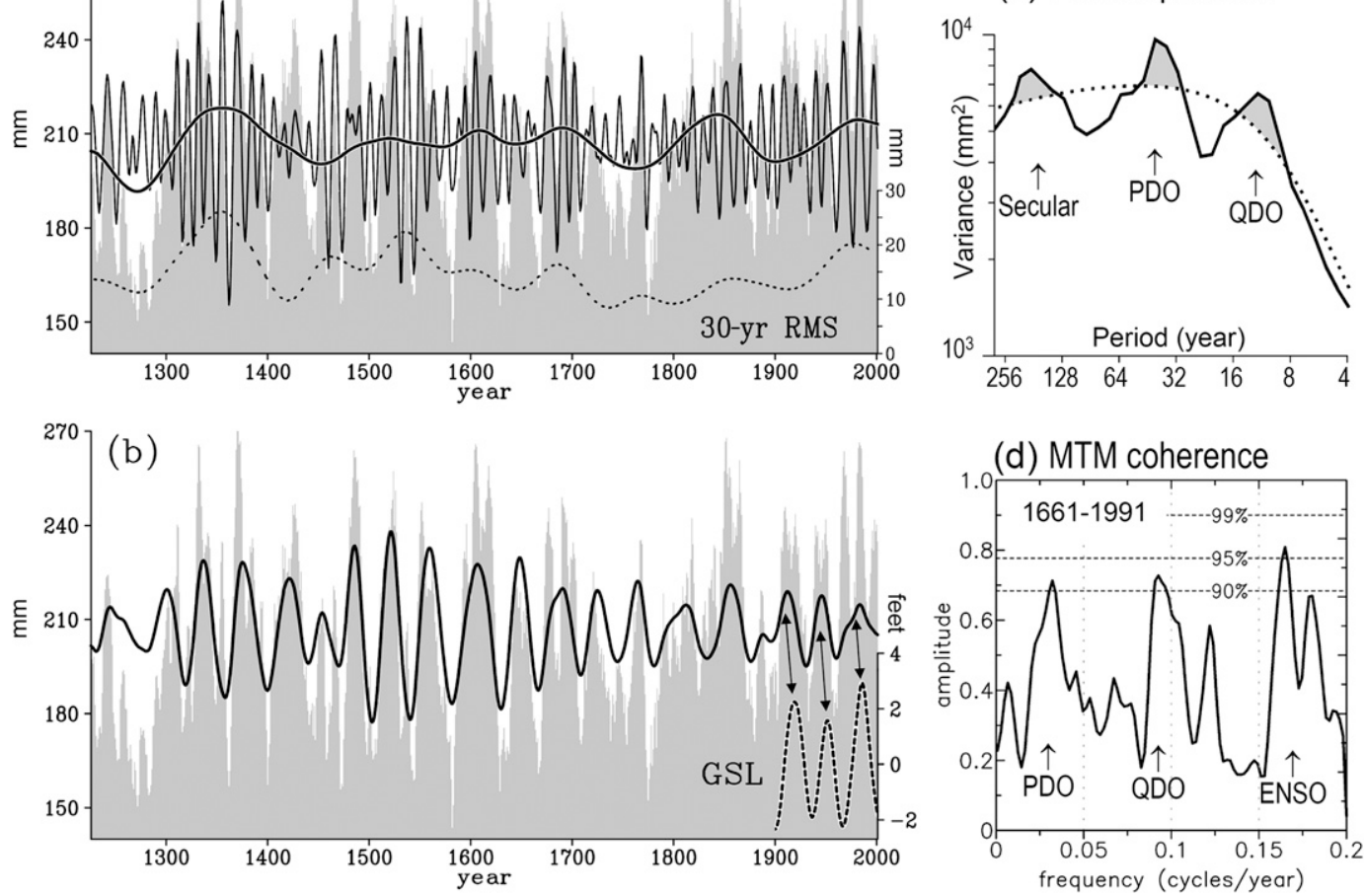

(d) MTM coherence

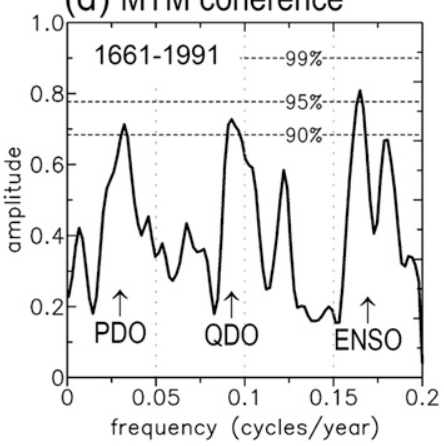

FIG. 12. Tree-ring reconstructed precipitation over northeast UT (Gray et al. 2004) lowpassed by 6 yr (gray histogram) superimposed with (a) the QDO (thin solid curve), the 150-200-yr mode (thick solid curve), and the 30-yr RMS of the QDO running through the data (dotted curve; see text). (b) As in (a), but superimposed with the 35-50-yr mode (solid curve) and the GSL elevation (lower-right dashed curve), both bandpassed by 35-50 yr with the HW filter. (c) The global wavelet power spectrum of the tree-ring precipitation from 1226 to 2001 superimposed with the red-noise 99\% significance level (dotted curve), following Figs. 3a-c. (d) MTM coherence between the tree-ring precipitation and the proxy PDO index constructed by Biondi et al. (2001) from 1661 to 1991. The three frequency bands corresponding to the PDO (interdecadal), QDO, and ENSO (interannual) modes are indicated.

present times, resulting in as much as $5 \frac{1}{2} \mathrm{~m}(18 \mathrm{ft})$ of lake level drop and rise in the GSL elevation once every $35-50$ yr!

Recent tree-ring chronologies have been developed to reconstruct proxy indices for atmospheric circulation patterns. The proxy PDO index constructed by Biondi et al. (2001) for the time period of 1661-91 was examined to shed light on possible teleconnection factors contributing to the precipitation variation in the Great Basin. (The tree-ring reconstructed precipitation and PDO proxies were provided by the NOAA/Paleoclimatology Program, see online at http://www.ncdc.noaa.gov/ paleo/recons.html.) The MTM coherence analysis between the tree-ring precipitation and the proxy PDO index (Fig. 12d) reveals three peaks in the 30-50-, 10-15-, and 4-5-yr frequency bands that are significant above the $90 \%$ confidence level. It is known that the PDO, which depicts the North Pacific SST variability north of $20^{\circ} \mathrm{N}$, contains both the interdecadal and interannual signals in the tropical Pacific (Zhang et al. 1997; Mantua et al. 1997). An increasing quasi-decadal signal in the late twentieth century has also been noted in the PDO (e.g., Minobe 1999). Therefore, the three coherence zones in Fig. 12d likely correspond to the PDO, QDO, and ENSO modes, respectively. The result supports the existence of the hydrological QDO in the Great Basin. Moreover, it suggests that the pronounced 35-50-yr cycle recorded in the GSL elevation may be related to the PDO, though how this relationship forms requires further investigation.

\section{Conclusions}

The variations of precipitation, streamflow, water vapor flux convergence, and drought conditions in the Great Basin are characterized by pronounced quasidecadal signals. The GSL integrates the hydrological QDO and forms the distinct 12-yr cycle in lake level fluctuations as was previously noted (LM95; Mann et al. 1995; and subsequent works). Multicentury records of proxy precipitation constructed from tree rings show that the magnitude of this quasi-decadal climate mode has been exceptionally pronounced during the past half 
century. Under the assumption that the current climate maintains its status, the pronounced hydrological QDO in this region points to a potential for better long-range (3-6 yr) climate prediction skills to develop based on its cyclical character.

The coherence between the GSL elevation and the Pacific QDO was examined. The precipitation QDO in the Great Basin responds to recurring circulation patterns over the Gulf of Alaska developing during the warm-to-cool and cool-to-warm transition phases of the Pacific QDO, which are embedded in an atmospheric short-wave train dissimilar to the ENSO-like PNA pattern. Such transition-phase circulation patterns induce abnormal synoptic transient activities across the central intermountain region, influence the water vapor flux convergence and divergence, and modulate the precipitation. Because of the quarter-phase $(\sim 3 \mathrm{yr})$ lag of the GSL elevation behind the precipitation, and the quarterphase lag of the precipitation in the wake of the warm/ cool-phase Pacific QDO, the underlining processes lead to a half-phase $(\sim 6 \mathrm{yr})$ delay in the GSL elevation from the warm/cool-phase Pacific QDO (cf. Fig. 4). This causes the opposite, yet coherent, phase relationship between the GSL elevation and the Pacific QDO.

A proper monitoring of the status of the Pacific QDO evolution may help predict the precipitation variation in the Great Basin and the GSL elevation for subsequent years. Previous studies using statistical models alone (Lall et al. 1996; Abarbanel and Lall 1996; Moon and Lall 1996) have demonstrated that the variations of the GSL elevation may be forecasted for up to $4 \mathrm{yr}$. Those studies have hinted, but have not explained, why it is that the pronounced QDO in the GSL elevation contributes to its relatively high predictability. The present study goes one step forward in revealing the physical link between the Pacific QDO and the hydrological QDO in the Great Basin, providing insight to necessary processes involved in developing long-range climate prediction capabilities for the central intermountain region.

It is well known that the teleconnectional impacts of tropical and North Pacific variability on the western United States climate are most significant in the Northwest and the Southwest-with the Great Basin located in the marginal area (cf. Figs. 5 and 9a). The results of this study suggest that the central intermountain region is particularly sensitive to the atmospheric teleconnection developed in the transition phases, rather than the warm and cool phases, of the Pacific QDO. In fact, the strong coherence between the GSL elevation and the Pacific QDO serves to verify these processes, because of the impossibility for the GSL to simultaneously respond to any teleconnection pattern. The impact of such a transition-phase teleconnection of the Pacific QDO (and perhaps other oscillating modes) on the global hydrological cycle deserves further attention.

Acknowledgments. We are grateful to Alessandra Iacobucci at CEREMADE-CNRS, University of ParisDauphine, for providing the HW filter package, to Upmanu Lall at Columbia University for sharing with us the MTM spectral analysis program, and to Michael Mann at Penn State University for making many useful statistical tools available. Comments offered by the reviewers have been very helpful in improving the manuscript and are highly appreciated. We thank Marty Booth for the editorial assistance and Jennie Shipley for preparing the COOP station data. This study was supported by the USDA-CSREES funded Drought Management, Utah Project, and approved by the Utah Agricultural Experiment Station, Utah State University, as Journal Paper 8052.

\section{REFERENCES}

Abarbanel, H. D. I., and U. Lall, 1996: Nonlinear dynamics of the Great Salt Lake: System identification and prediction. Climate Dyn., 12, 287-297.

Allan, R. J., 2000: ENSO and climatic variability in the last 150 years. El Niño and the Southern Oscillation: Multiscale Variability, Global and Regional Impacts, H. F. Diaz and V. Markgraf, Eds., Cambridge University Press, 3-56.

_ historical gridded mean sea level pressure data set (HadSLP2): 1850-2004. J. Climate, 19, 5816-5842.

Barlow, M., S. Nigam, and E. H. Berbery, 2001: ENSO, Pacific decadal variability, and U.S. summertime precipitation, drought, and streamflow. J. Climate, 14, 2105-2128.

Biondi, F., A. Gershunov, and D. R. Cayan, 2001: North Pacific decadal climate variability since 1661 . J. Climate, 14, 5-10.

Blackmon, M. L., 1976: A climatological spectral study of the 500-mb geopotential height of the Northern Hemisphere. J. Atmos. Sci., 33, 1607-1623.

Cayan, D. R., and J. O. Roads, 1984: Local relationships between U.S. west coast precipitation and monthly mean circulation parameters. Mon. Wea. Rev., 112, 1276-1282.

, K. T. Redmond, and L. G. Riddle, 1999: ENSO and hydrologic extremes in the western United States. J. Climate, 12, 2881-2893.

Chen, T.-C., 1985: Global water vapor flux and maintenance during FGGE. Mon. Wea. Rev., 113, 1801-1819.

Cook, E. R., D. M. Meko, D. W. Stahle, and M. K. Cleaveland, 1999: Drought reconstructions for the continental United States. J. Climate, 12, 1145-1162.

Dai, A., K. E. Trenberth, and T. Qian, 2004: A global data set of Palmer Drought Severity Index for 1870-2002: Relationship with soil moisture and effects of surface warming. J. Hydrometeor., 5, 1117-1130.

Dettinger, M. D., D. R. Cayan, H. F. Diaz, and D. M. Meko, 1998: North-south precipitation patterns in western North America on interannual-to-decadal timescales. J. Climate, 11, 3095-3111. 
Ely, L. L., Y. Enzel, and D. R. Cayan, 1994: Anomalous North Pacific atmospheric circulation and large winter floods in the southwestern United States. J. Climate, 7, 977-987.

Gershunov, A., and T. P. Barnett, 1998: Interdecadal modulation of ENSO teleconnections. Bull. Amer. Meteor. Soc., 79, 2715-2725.

Gray, S. T., S. T. Jackson, and J. L. Betancourt, 2004: Tree-ring based reconstructions of interannual to decadal-scale precipitation variability for northeastern Utah. J. Amer. Water Resour. Assoc., 40, 947-960.

Hamming, R. W., 1998: Digital Filters. 3rd ed. Dover Publications, 296 pp.

Harnack, R. P., D. T. Jensen, and J. R. Cermak, 1998: Investigation of upper-air conditions occurring with heavy summer rain in Utah. Int. J. Climatol., 18, 701-723.

Hasselmann, K., 1976: Stochastic climate models I: Theory. Tellus, 28, 473-485.

Hassibe, W. R., 1991: The Great Salt Lake. U.S. Department of the Interior/U.S. Geological Survey, U.S. Government Printing Office, $24 \mathrm{pp}$.

Hidalgo, H. G., and J. A. Dracup, 2003: ENSO and PDO effects on hydroclimatic variations of the Upper Colorado River basin. J. Hydrometeor., 4, 5-23.

Iacobucci, A., and A. Noullez, 2005: A frequency selective filter for short-length time series. Comput. Econ., 25, 75-102.

Jin, J., N. L. Milller, S. Sorooshian, and X. Gao, 2006: Relationship between atmospheric circulation and snowpack in the western United States. Hydrol. Processes, 20, doi:10.1002/hyp.6126.

Kalnay, E., and Coauthors, 1996: The NCEP/NCAR 40-Year Reanalysis Project. Bull. Amer. Meteor. Soc., 77, 437-471.

Kaplan, A., M. Cane, Y. Kushnir, A. Clement, M. Blumenthal, and B. Rajagopalan, 1998: Analyses of global sea surface temperature 1856-1991. J. Geophys. Res., 103, 567-589.

Karoly, D., R. A. Plumb, and M. Ting, 1989: Examples of the horizontal propagation of quasi-stationary waves. J. Atmos. Sci., 46, 2802-2811.

Keppenne, C. L., and M. Ghil, 1992: Adaptive filtering and prediction of the Southern Oscillation Index. J. Geophys. Res., 97, 20 449-20 454.

King, B., and Coauthors, 2007: Drought in Utah: Learning from the past-preparing for the future. Utah State Water Plan, Utah Division of Water Resources, 124 pp.

Lall, U., and M. Mann, 1995: The Great Salt Lake: A barometer of low-frequency climatic variability. Water Resour. Res., 31, 2503-2515.

— T. Sangoyomi, and H. D. I. Abarbanel, 1996: Nonlinear dynamics of the Great Salt Lake: Nonparametric forecasting. Water Resour. Res., 32, 975-985.

Latif, M., and T. Barnett, 1994: Causes of decadal climate variability over the North Pacific and North America. Science, 266, 634-637.

— , and — 1996: Decadal climate variability over the North Pacific and North America: Dynamics and predictability. J. Climate, 9, 2407-2423.

Legates, D. R., and C. J. Willmott, 1990: Mean seasonal and spatial variability in gauge-corrected, global precipitation. Int. J. Climatol., 10, 111-127.

Leung, L. R., Y. Qian, and X. Bian, 2003: Hydroclimate of the western United States based on observations and regional climate simulation of 1981-2000. Part I: Seasonal statistics. J. Climate, 16, 1892-1911.

Lohmann, K., and M. Latif, 2005: Tropical Pacific decadal variability and the subtropical-tropical cells. J. Climate, 18, 51635178.
Mann, M. E., 2004: On smoothing potentially non-stationary climate time series. Geophys. Res. Lett., 31, L07214, doi:10.1029/ 2004 GL019569.

—_, and J. Park, 1996: Greenhouse warming and changes in the seasonal cycle of temperature: Model versus observation. Geophys. Res. Lett., 23, 1111-1114.

_- U. Lall, and B. Saltzman, 1995: Decadal and secular climate variability: Understanding the rise and fall of the Great Salt Lake. Geophys. Res. Lett., 22, 937-940.

Mantua, N. J., S. R. Hare, Y. Zhang, J. M. Wallace, and R. C. Francis, 1997: A Pacific interdecadal climate oscillation with impacts on salmon production. Bull. Amer. Meteor. Soc., 78, 1069-1079.

Minobe, S., 1999: Resonance in bidecadal and pentadecadal climate oscillations over the North Pacific: Role in climatic regime shifts. Geophys. Res. Lett., 26, 855-858.

Moller, A. L., and R. R. Gillies, 2008: Utah Climate. 2nd ed. Utah Climate Center, Utah State University, 109 pp. [Available online at http://climate.usu.edu.]

Moon, Y.-I., and U. Lall, 1996: Large scale atmospheric indices and the Great Salt Lake: Interannual and interdecadal variability. J. Hydrol. Eng., 1, 55-62.

Neelin, J. D., 2007: Moist dynamics of tropical convection zones in monsoons, teleconnections, and global warming. The Global Circulation of the Atmosphere, T. Schneider and A. H. Sobel, Eds., Princeton University Press, 267-301.

Oppenheim, A. V., and R. V. Schafer, 1999: Discrete-Time Signal Processing. 2nd ed. Prentice-Hall, 870 pp.

Peixoto, J. P., and A. Oort, 1992: The Physics of Climate. SpringerVerlag, 520 pp.

Philander, S. G. H., 1990: El Niño, La Niña, and the Southern Oscillation. Academic Press, 293 pp.

Plumb, R., 1985: On the three-dimensional propagation of stationary waves. J. Atmos. Sci., 42, 217-229.

Rasmusson, E. M., 1967: Atmospheric water vapor transport and the water valance of North America. Part I: Characteristics of the water flux field. Mon. Wea. Rev., 95, 403-426.

Roads, J. O., S. C. Chen, A. K. Guetter, and K. P. Geogakakos, 1994: Large-scale aspects of the U.S. hydrologic cycle. Bull. Amer. Meteor. Soc., 75, 1589-1610.

Sangoyomi, T. B., 1993: Climatic variability and dynamics of Great Salt Lake hydrology. Ph.D. dissertation, Utah State University, $247 \mathrm{pp}$.

_, U. Lall, and H. D. I. Abarbanel, 1996: Nonlinear dynamics of the Great Salt Lake: Dimension estimation. Water Resour. Res., 32, 149-160.

Shafer, J. C., and W. J. Steenburgh, 2008: Climatology of strong intermountain cold fronts. Mon. Wea. Rev., 136, 784-807.

Shanahan, T. M., J. T. Overpeck, W. E. Sharp, C. A. Scholz, and J. A. Arko, 2007: Simulating the response of a closed-basin lake to recent climate changes in tropical West Africa (Lake Bosumtwi, Ghana). Hydrol. Processes, 21, 1678-1691.

Smirnov, V. V., and G. W. K. Moore, 1999: Spatial and temporal structure of atmospheric water vapor transport in the Mackenzie River basin. J. Climate, 12, 681-696.

Torrence, C., and G. P. Compo, 1998: A practical guide to wavelet analysis. Bull. Amer. Meteor. Soc., 79, 61-78.

Tourre, Y. M., B. Rajagopalan, Y. Kushnir, M. Barlow, and W. B. White, 2001: Patterns of coherent decadal and interdecadal climate signals in the Pacific Basin during the 20th century. Geophys. Res. Lett., 28, 2069-2072.

Wallace, J. M., and D. S. Gutzler, 1981: Teleconnections in the geopotential height field during the Northern Hemisphere winter. Mon. Wea. Rev., 109, 784-812. 
Wang, S.-Y., R. R. Gillies, J. Jin, and L. E. Hipps, 2009: Recent rainfall cycle in the intermountain region as a quadrature amplitude modulation from the Pacific decadal oscillation. Geophys. Res. Lett., 36, L02705, doi:10.1029/2008GL036329.

,-- L. E. Hipps, and J. Jin, 2010: A transition-phase teleconnection of the Pacific quasi-decadal oscillation. Climate Dyn., doi:10.1007/s00382-009-0722-5, in press.

White, W. B., and Y. M. Tourre, 2003: Global SST/SLP waves during the 20th century. Geophys. Res. Lett., 30, 1651, doi:10.1029/ 2003 GL017055.
- and Z. Liu, 2008a: Non-linear alignment of El Niño to the 11-yr solar cycle. Geophys. Res. Lett., 35, L19607, doi:10.1029/ 2008GL034831.

$\longrightarrow$, and $-2008 \mathrm{~b}$ : Resonant excitation of the quasi-decadal oscillation by the 11-year signal in the Sun's irradiance. J. Geophys. Res., 113, C01002, doi:10.1029/2006JC004057.

Yoon, J. H., and T. C. Chen, 2006: Maintenance of the boreal forest rainbelts during northern summer. J. Climate, 19, 1437-1449.

Zhang, Y., J. M. Wallace, and D. S. Battisti, 1997: ENSO-like interdecadal variability: 1900-93. J. Climate, 10, 1004-1020. 